NBER WORKING PAPER SERIES

\title{
POLITICS 2.0: THE MULTIFACETED EFFECT OF BROADBAND INTERNET ON POLITICAL PARTICIPATION
}

\author{
Filipe R. Campante \\ Ruben Durante \\ Francesco Sobbrio \\ Working Paper 19029 \\ http://www.nber.org/papers/w19029
}

\author{
NATIONAL BUREAU OF ECONOMIC RESEARCH \\ 1050 Massachusetts Avenue \\ Cambridge, MA 02138 \\ May 2013
}

We are very grateful to "Osservatorio Banda Larga-Between" for providing us access to the data on ADSL coverage of Italian municipalities used in this paper. We also thank Nicola D'Amelio and Giuseppe Piraino for their help with data collection, and Stefano Gagliarducci for sharing his dataset on Italian municipal elections. We thank Adriana Camacho, Stefano DellaVigna, Matthew Ellman, Leopoldo Fergusson, Ed Glaeser, Rema Hanna, Andrea Ichino, Andrea Mattozzi, Luke Miner, Luigi Pascali, Nicola Persico, Giacomo Ponzetto, Andrei Shleifer, David Yanagizawa-Drott, and seminar participants at the European University Institute, Harvard University, the Institut d'Anàlisi Econòmica, Tufts University, Universitat Pompeu Fabra, and at the X Workshop in Media Economics (Bogotá). Maria Chiara Cavalleri and Marta Fana provided excellent research assistance. Finally, special thanks go to Silvio Berlusconi for forcing early elections in 2013 and thus expediting our data collection process. The usual disclaimers apply. The views expressed herein are those of the authors and do not necessarily reflect the views of the National Bureau of Economic Research.

NBER working papers are circulated for discussion and comment purposes. They have not been peerreviewed or been subject to the review by the NBER Board of Directors that accompanies official NBER publications.

(C) 2013 by Filipe R. Campante, Ruben Durante, and Francesco Sobbrio. All rights reserved. Short sections of text, not to exceed two paragraphs, may be quoted without explicit permission provided that full credit, including (C) notice, is given to the source. 
Politics 2.0: The Multifaceted Effect of Broadband Internet on Political Participation Filipe R. Campante, Ruben Durante, and Francesco Sobbrio

NBER Working Paper No. 19029

May 2013, Revised October 2013

JEL No. D72,L82,L86

\begin{abstract}
$\underline{\text { ABSTRACT }}$
We investigate the causal impact of broadband Internet on political participation using data from Italy. We show that this impact varies across different forms of political engagement and over time. Initially, broadband had a negative effect on turnout in national elections, driven by increased abstention of ideologically extreme voters. Meanwhile, however, broadband fostered other forms of online and offline participation. Over time, the negative effect was reverted due to the emergence of new political entrepreneurs who used the Internet to convert the initial "exit" back into "voice". Overall, these nuanced effects underscore the general equilibrium dynamic induced by the Internet.
\end{abstract}

Filipe R. Campante

Harvard Kennedy School

79 JFK Street

Cambridge, MA 02138

and NBER

filipe_campante@harvard.edu

Ruben Durante

Department of Economics, Sciences Po

28, rue des Saints Pères

75007 Paris France

Ruben.Durante@sciences-po.org
Francesco Sobbrio

Catholic University of Milan

Largo Gemelli 1

20123, Milano

Italy

francesco.sobbrio@unicatt.it 


\section{INTRODUCTION}

The advent of the Internet has dramatically transformed the way individuals obtain, produce, and exchange information. There is a widespread belief that such a revolution is likely to have a profound impact on various dimensions of social life, not the least on politics. ${ }^{1}$

Several competing hypotheses have been advanced regarding the possible impact of Internet on political participation. A positive view is that the Internet makes it easier for citizens to acquire political information from more and more diverse sources, and, to the extent that better-informed citizens tend to be more participative (Feddersen and Pesendorfer, 1996, 1999; Lassen, 2005), it should therefore increase political participation. A less optimistic view focuses instead on the possibility that, since the Internet provides unprecedented entertainment opportunities, individuals may devote less time to informing themselves about politics and, by the same token, will ultimately be less informed and less engaged.

Others have instead emphasized the importance of the Internet as a coordination device, and its potential to facilitate collective action. As stated by Kevin Werbach, "The internet fundamentally lowers the barriers to organization [...] Like-minded souls no longer need painstakingly to build an organizational structure; a mailing-list is often enough to band together online" (The Economist, Jan 5, 2013). This would also lead, presumably, to increased political participation, though here again the coordinating role of the Internet could be devoted to non-political activities that might crowd out the political kind.

Set against these multiple possibilities, estimating the causal impact of the Internet on political participation is a challenging empirical task, for several reasons. First, and quite obviously, Internet access is likely to be correlated with a variety of relevant socio-economic characteristics that may influence political participation through other channels. Second, and at least as important, the introduction of such a revolutionary technology is likely to trigger complex transformations, both on what we may call the "demand" and the "supply" sides of politics. Put simply, the Internet changes the incentives and technological possibilities available to political actors, so that its effects in the short and in the long run, once "general equilibrium" repercussions are taken into account, may differ considerably.

This paper tackles these questions in the context of the introduction of high-speed (broadband) Internet in Italy, a developed country with solid democratic institutions, but where traditional media, such as TV and newspapers, are largely controlled by the government or by powerful private interests. To do so, we exploit differences in the timing of the introduction of broadband (ADSL) technology across Italian municipalities, between 2005 and 2011, to analyze how access to high-speed internet affected individuals' decisions with regard to different forms of political involvement.

To deal with the endogeneity in the access to broadband Internet, we exploit the fact that the diffusion

\footnotetext{
${ }^{1}$ See Larcinese and Miner (2012) for several interesting pieces of anecdotal evidence on views regarding the economic and political consequences of the Internet, and Hindman (2009) and Farrell (2012) for an overview of the debate among scholars and political activists.
} 
of ADSL technology in a given municipality is affected by its relative position in the pre-existing voice telecommunications infrastructure. Specifically, we use the distance between a given municipality and the closest high-order telecommunication exchange ("Urban Group Stage", UGS) - which represents a good proxy for the investment required to connect the municipality - as a source of exogenous variation for the availability of high-speed internet. Since the pre-existing infrastructure was not randomly distributed, our identification strategy relies on interacting that distance with the time variation between the period before and after broadband became available, under the assumption that the correlation between distance and unobserved municipal characteristics did not change at that point in time, other than through the introduction of the Internet.

Our findings point to a complex chain of effects in which the impact of broadband internet availability changes over time and is crucially affected by the reaction of the political "supply side". We first document that the diffusion of broadband led, initially, to a significant decline in electoral turnout in national parliamentary elections between 1996-2001 (pre-broadband) and 2006-2008 (post-broadband). This effect is sizeable - about 7 percentage points for going from zero to full broadband access and very robust to the use of various measures of broadband access and various specifications. Interestingly, we find that this initial negative effect of Internet on turnout was largely reversed in the following elections, held in 2013.

To shed light on this nuanced pattern, we first document that the initial decline in turnout was especially detrimental to the electoral performance of "outsider" parties - i.e. ideologically extreme forces outside the mainstream coalitions - whose supporters are generally well informed and politically active. This is consistent with the diffusion of Internet having led to a particularly engaged but disenchanted segment of the electorate dropping out of the mainstream electoral process.

At the same time, we find that Internet diffusion fostered other forms of political participation. First, using a unique data set on the geographic distribution of local grassroots protest groups organized through the online platform Meetup.com, we show that the diffusion of broadband was associated with these groups forming earlier and growing faster. More interestingly, the strength of the online local groups soon translated into greater support for the Five-Star Movement (M5S), a largely web-based political movement that coalesced around those online groups and gradually evolved into a potent electoral force. Indeed, looking at local elections starting in 2008, we document that broadband access was positively associated with the presence of the M5S on the ballots, and with electoral support for the M5S lists. In addition, we document that turnout in the 2009 and 2011 national referenda - which had a distinct anti-establishment flavor - was actually higher in better connected municipalities.

These results suggest that political entrepreneurs eventually seized the opportunity of using the Internet to fish into the pool of disenchanted (but engaged and "connected") individuals that the Internet itself had initially contributed to create, favoring their return to mainstream electoral politics. This tendency is confirmed by the results for the 2013 parliamentary elections, when the M5S first run at the national level, and which show a positive effect of broadband access on the electoral performance of the M5S and other new "web-friendly" parties. 
In sum, our evidence underscores what we may call the "general-equilibrium" repercussions of the change in media technology exemplified by the onset of high-speed Internet. That shock entails a shift on the "demand side" of the political process, as voters react to the new medium; this, however, is merely the first reaction in the more complex chain. Eventually, political entrepreneurs on the supply side take advantage of the opportunity presented by the initial demand-side movement - and by the possibilities and low barriers to entry that characterize the new medium itself - to enhance political mobilization in ways that eventually feed back and alter the initial landscape. Quite simply, using the classic framework of "exit, voice, and loyalty" (Hirschman, 1970), it seems that the new medium initially constituted an "exit" option from the mainstream political process, but was eventually harnessed into a new "voice" mechanism within that process.

This framework makes clear that this exit-to-voice transition is quite natural, once we consider that the effect of that mainstream political process on public-good provision ought to induce Hirschmanian "loyalty": it is essentially impossible to completely exit its reach (at least short of emigration). In addition, while we might expect a similar pattern to hold with different instances of shifts in media technology, that transition seems especially relevant for the case of the Internet. Its interactivity and prevalence of user-generated content translate into relatively low barriers to entry, and make it particularly suited for exploitation by a wide range of political actors, including newcomers. Grasping these general equilibrium effects is thus crucial to understanding the political impact of changes in the media environment, and particularly so for the Internet.

Our paper relates to the vast literature on the role of mass media and information in the political process, and on what it would lead us to expect from the diffusion of the Internet. ${ }^{2}$ While many studies on episodes of new media technologies have found a positive effect on turnout (e.g. Strömberg, 2004 on radio, Gentzkow, Shapiro, and Sinkinson, 2011 on newspapers), some have documented the possibility of negative effects on electoral participation due to a crowding-out effect over traditional (and potentially more informative) media (e.g. Gentzkow, 2006 on television). Our empirical evidence is consistent with the presence of a (short-run) negative effect, but it qualifies its nature; in particular, we show that the individuals who dropped out initially as a result of broadband expansion were relatively more likely to be politically informed and engaged. This makes it unlikely that the demobilization we identify would have been induced by simple crowding out. In addition, it highlights that the political equilibrium reacts in ways that may eventually compensate for any initial demobilization.

Our work also relates to the incipient literature on the specific link between Internet and electoral politics. ${ }^{3}$ Specifically, a few recent contributions have exploited within-country variation in broadband availability to assess the impact of the Internet on political outcomes, and turnout in particular. Miner (2012) examines the effect of Internet use on voting behavior in Malaysia, instrumenting In-

\footnotetext{
${ }^{2}$ See Prat and Strömberg (2011) for an extensive literature review on the political economy of media.

${ }^{3}$ More broadly, our work relates to the literature on the political economy of the Internet which includes, among others, Gentzkow and Shapiro (2011), Enikolopov, Petrova, and Sonin (2012), Larcinese and Miner (2012), and Jaber (2013).
} 
ternet penetration with the distance of each electoral district from the backbones of Malaysia's main Internet Service Providers (ISPs). He finds that Internet penetration increased turnout and decreased the electoral returns of the incumbent party. Czernich (2012) and Falck, Gold, and Heblich (2012) look instead at the effects of Internet on turnout and electoral competition in Germany. In spite of using a similar empirical strategy based on other technical features of ADSL technology, they find contrasting results on turnout (positive and insignificant versus negative, respectively). Finally, exploiting differences across U.S. states in right-of-way (ROW) laws, Larcinese and Miner (2012) find a positive effect on the Democratic party's vote share but no significant effect on turnout.

Our paper differs from these contributions in many respects. In terms of empirical strategy, using not only the position of different localities in the pre-existing voice telecommunication infrastructure, but also its interaction with time, considerably strengthens identification. Specifically, the longitudinal dimension of our data and the characteristics of our instrumental variable allow us to control for both time-invariant municipal characteristics and differential trends related to relevant demographics. Just as significantly, it allows us to estimate our effect on the entire sample, rather than relying on a restricted set of peculiar localities. Most importantly, from a conceptual point of view, our contribution emphasizes the general equilibrium implications of the introduction of the Internet, how its impact can vary over time, across different forms of online and offline participation, and interact with the evolution of the political supply, all aspects that previous contributions have not been able to address. While the short-run impact on voter turnout is certainly relevant, our approach provides a unified perspective on the ultimate chain of effects, and shows that it can be very different from those partial-equilibrium effects.

The remainder of the paper is organized as follows. Section 2 introduces the conceptual framework that will guide the interpretation of our empirical findings. Section 3 provides relevant background information on the diffusion of broadband in Italy and on the Italian institutional and political landscape over the period under examination. Section 4 describes the data and the empirical strategy. Section 5 presents the results on the impact of broadband on turnout in parliamentary elections, while Section 6 discusses some evidence on other forms of participation that can help elucidate the mechanism at work. Section 7 concludes by summarizing our interpretation of the main findings, and discussing alternative mechanism and external validity.

\section{CONCEPTUAL FRAMEWORK}

We start off with a brief conceptual discussion of the possible effects of broadband Internet on political participation, to provide some structure to interpret our empirical results.

Why should the advent of the Internet matter for political engagement? First, the Internet constitutes a new media technology providing users with a variety of new content, thus changing individual incentives to acquire political information. On the one hand, the existing evidence has established that, if a new medium makes it easier for individuals to do so from more and more diverse sources, 
its introduction could foster political participation. However, if it crowds out traditional sources of political information - for example by providing new entertainment content - its introduction could discourage political participation. This latter possibility seems particularly relevant for the case of the Internet, which has brought along unprecedented levels of politically-related content, but also virtually unlimited entertainment opportunities. It is thus natural that most of the fledgling literature on its political impact has focused on this tension (Czernich, 2012; Falck, Gold, and Heblich, 2012).

The Internet is, however, much more than just another source of information and entertainment. Quite uniquely when compared to other media, it represents a powerful (and relatively cheap) platform for political discussion and participation, and for coordinating the actions of politically like-minded individuals. Although undoubtedly the advent of social media has greatly expanded these opportunities for online political participation, these existed long before in various forms: from posting comments on political blogs to politically-related emailing lists, inter alia. It is thus quite clear that, though certainly important, increased availability of information and entertainment is not necessarily the only channel through which the Internet might affect political behavior.

To make sense of the implications of these multiple channels when it comes to political participation, we resort to the celebrated framework of "exit, voice, and loyalty" proposed by Hirschman (1970), which attempts to explain how individuals may react to discontent regarding any organization of which they are part. In particular, in the context we analyze, we can think of mainstream democratic politics - namely, the process through which political office-holders are selected and monitored in an established democracy - as the organization of interest. The effect of broadband Internet on political participation will depend on how it may affect citizens' strategic options of exit - i.e. abstaining from turning out in elections - versus voice - i.e. voting, or otherwise engaging with the electoral process.

Our previous discussion underscores that the Internet clearly offers both voice and exit options. Those who are unhappy with mainstream politics can use online platforms to express their opinions about elections, and to try to articulate activities that will affect them. On the other hand, the Internet offers vast opportunities to drop out, either by tuning out of politics altogether, or by engaging with political activities outside of the electoral mainstream.

When should we expect each option to prevail? They key point is that different strategies of voice and exit will appeal to different types of (potential) voters, according to their levels of intrinsic political engagement and of satisfaction with mainstream politics. All else equal, more engaged individuals will presumably be less likely to tune out of politics altogether; similarly, individuals satisfied with the existing state of the mainstream political process will be less likely to drop out. We summarize these distinctions with the simple $2 \times 2$ matrix presented in Table 1 .

To the extent that there are many voters who are either dissatisfied or relatively disengaged, the Internet is likely to have an immediate negative impact on participation in the mainstream political process, as both groups will take advantage of the improved exit options offered by the new technology. However, each of these two groups' dropping out is likely to have very different long-term consequences, 
as they would pose very different incentives to political actors.

Individuals who have dropped out but are politically engaged constitute a pool of prospective voters who are likely to return to active participation, as long as someone caters to their preferences and addresses some of the sources of their discontent. The prospect of fishing in this pool obviously constitutes a pulling factor for political entrepreneurs to whom, in addition, the Internet itself offers many new avenues for engaging with these potential voters. Quite significantly, the Internet imposes very low barriers to entry, making these opportunities easily available even to those with limited resources, and thus facilitating access by new political movements.

It follows that - as long as there is widespread voter disenchantment, as opposed to mere disengagement - the diffusion of broadband access creates a demand for those political entrepreneurs to fill, and provides them with powerful tools to tap into that demand opening vast possibilities to convert the initial exit from mainstream electoral politics back into voice. As a consequence, the long-run, general-equilibrium effect of the introduction of broadband Internet - that is, after taking into the account the reaction from the "supply side" of politics - can be very different from its short-term impact, and precisely because of the incentives that the latter poses.

We can further predict that such reversal is actually quite likely, again with reference to the standard Hirschmanian framework, and specifically to the concept of "loyalty" induced by an organization. With no particular moral connotation, the term here rather refers to how hard it is for an individual to exit that organization. While it is a basic tenet that exit tends to drive out voice, it remains true that the mainstream political process is a crucial driver of policy choices and public good (or bad) provision; as such, it inevitably affects even those who have opted for exit. This exemplifies a situation such that "full exit is impossible; in some sense, one remains (...) a member of the organization in spite of formal exit." (Hirschman, 1970, p.100) These are precisely the situations in which loyalist behavior with respect to the organization is most likely. In other words, there will likely be sufficient underlying loyalty so as to provide an opportunity for those who could devise, from the new medium, new voice options that could be brought to the mainstream.

In sum, this interpretation suggests a nuanced interplay between "voice" and "exit" strategies. Moreover, such mechanism clearly underscores the importance of the general equilibrium effects in any episode of diffusion of high-speed Internet - and more broadly, for any change in media environment. Quite simply, we should expect its effects to shift over time - from exit back to voice - once the supply side of politics has endogenously responded to the initial shock, precisely by targeting the inflated contingent of demobilized (but politically engaged) voters. 


\section{BACKGROUND}

\subsection{BROADBAND INTERNET IN ITALY}

Broadband Internet connection to residential customers in Italy has been traditionally provided through Asymmetric Digital Subscriber Line (ADSL) technology, while the use of alternative technologies, such as cable and satellite, has remained negligible (OECD, 2001; Between, 2008). ${ }^{4}$ ADSL technology was introduced by the Italian telecommunications incumbent operator (Telecom Italia) in 1999; the broadband infrastructure developed rather slowly at first, but at a faster pace in the following years. If by the end of 2000 only 117 out of 8,100 Italian municipalities had access to ADSL, by the end of 2005 ADSL was available in about half of them, accounting for about $86 \%$ of the population. Figure 1 summarizes the evolution in Italy of both the availability of ADSL Internet access (panel A), and Internet penetration in terms of the share of population with an ADSL subscription (panel B), between the end of 2000 and 2011, with election years marked by dashed vertical lines. Because in 2001 the levels of access and penetration were very small, we take this to be the last "pre-broadband" election cycle.

ADSL technology typically relies on data transmission over the user's copper telephone line, and as a result access to ADSL depends crucially on the user's position in the pre-existing voice telecommunications infrastructure. Two technical parameters are especially important in this regard. The first one is the length of the so-called "local loop", i.e. the distance between the end user's premises and the closest telecommunication exchange (or "central office", henceforth $\mathrm{CO}$ ). If this distance is above a certain threshold (between 4 and $5 \mathrm{~km}$ ), the ADSL connection cannot be implemented through traditional copper wires, but instead requires the deployment of fiber optic cables between the $\mathrm{CO}$ and the user's premises. This procedure involves significant costs since, unlike copper wires, fiber optic cables need to be laid underground. The second parameter is the distance between the $\mathrm{CO}$ and the closest higher-order telecommunication exchange, the Urban Group Stage (UGS), corresponding to the portion of the network referred to as "backhaul". For a given area to have access to ADSL, the respective $\mathrm{CO}$ must be connected to the closest UGS through fiber optic cables. ${ }^{5}$

In the context of Italy, the first parameter has not constituted a limiting factor to the development of the broadband infrastructure since, unlike other countries, Italy's voice telecommunications network has traditionally been characterized by a very short average length of the local loop: more than $95 \%$ of end users are located at less than $4 \mathrm{~km}$ from the closest $\mathrm{CO}$, and about $100 \%$ at less than $5 \mathrm{~km}$ (OECD, 2001, see Figure B.1 in Appendix).This situation has allowed telecom operators to provide ADSL access in most municipalities through a system, the "Fiber To The Exchange" (FTTE), that requires the deployment of fiber optic cables between UGSs and COs, but not between COs and end

\footnotetext{
${ }^{4}$ Definitions of broadband Internet access vary widely (OECD, 2001, p.6). The most common definition of "broadband" adopted by many telecommunications operators as well as by the OECD refers to technologies that allow for data download speed of at least $256 \mathrm{Kbps}$. At the end of 2007, ADSL technology accounted for more than $97 \%$ of broadband access in Italy (Between, 2008).

${ }^{5}$ For more details on the technical background regarding ADSL in Italy, see Appendix B.
} 
users' premises (see Figure B.2 for an illustration of the FTTE system).

Consequently, the distance between a municipality's COs and the closest UGS - which, quite importantly, was completely irrelevant for voice communication purposes - represents the main determinant of the investment needed to provide access to ADSL in that municipality. Indeed, this distance and the necessity to cover it using optical fiber cables has been the main factor behind the delay in ADSL adoption experienced by different municipalities over time (Ciapanna and Sabbatini, 2008). What is important for the purposes of our analysis is that, since the 10,700 COs and the 628 UGSs were inherited from the pre-existing voice telecommunication system, their location was determined several decades before the advent of the Internet (Impiglia et al. 2004, AGCOM, 2011). Hence, all else equal, the closer to an UGS a municipality happened to be when ADSL came into the picture, the more likely that a telecom operator would have provided that municipality with ADSL access earlier on in the diffusion process. ${ }^{6}$

For a given distance between the $\mathrm{CO}$ and the closest UGS, of course, the decision of whether to provide ADSL access to a given municipality also depends on a range of socio-demographic factors which can affect the expected commercial return of the investment, i.e. population density, income and education levels, etc. Indeed, ADSL technology was introduced earlier in more densely populated areas, typically urban and suburban. Figure 2 reports the distribution of access to broadband internet across Italian municipalities in 2005, the first year for which data are available, with ADSL availability increasing from dark (no access) to light (complete access).

\subsection{Political AND Institutional BACKGROUND (1996-2013)}

Italy is a parliamentary democracy characterized by a bicameral legislative system consisting of a lower and an upper house (Chamber of Deputies and Senate). ${ }^{7}$ Five national legislative elections have been held over the past seventeen years, in 1996, 2001, 2006, 2008, and 2013. This is the period we focus on, as it constitutes the set of elections since the collapse of the Italian post-World War II party system (the "First Republic"), in 1994, in the wake of the widespread corruption that was brought to light in the early 1990s by the set of judicial investigations that became known as Mani Pulite ("Clean Hands").

Over most of the period, right up to the 2013 elections, the Italian political landscape was largely dom-

\footnotetext{
${ }^{6}$ Notice that the cost of supplying ADSL to a municipality is increasing in the distance to the closest UGS not just because of the cost of fiber optic cables and excavation per se. Telecommunication operators typically need the authorization of the municipalities where these cables have to be deployed (Ciapanna and Sabbatini, 2008). Similarly, private landowners may, in principle, also delay the development of the broadband infrastructure when cable deployment involves their private property. As shown by Larcinese and Miner (2012) for the US, these dimensions are quite relevant in determining the bureaucratic costs that Internet Service Providers (ISPs) have to incur in order to provide broadband internet in a given geographical area. Hence, the farther away the closest UGS is, the higher these bureaucratic costs are likely to be.

${ }^{7}$ While all Italians aged 18 or more are entitled to vote for the Chamber, only those aged 25 or more can vote for the Senate.
} 
inated by two main coalitions, from the center-right and the center-left, whose we will later describe in greater detail. The center-right coalition, led by Silvio Berlusconi, owner of Italy's largest private media conglomerate, has typically included the heirs to the former fascist party, a northern separatist party (the Northern League), and, until 2006, part of the former Christian-Democrats. The center-left coalition includes part of the former communist party, left-leaning former Christian-Democrats, and a few smaller parties. Both coalitions comprise a bigger and relatively moderate party, which accounts for a very large share of the coalition's votes, alongside smaller and more ideologically extreme ones.

Despite the presence of these two coalitions, the Italian political system has remained relatively fragmented, with more than thirty parties running in each election, and parties outside the mainstream coalitions attracting significant electoral support. This tendency was even more pronounced in 2013, with the presence of a centrist coalition led by former prime minister Mario Monti, and, most importantly, the considerable electoral performance of the Five-Star Movement (henceforth M5S), led by blogger and former comedian Beppe Grillo.

In addition to national parliamentary elections, our analysis will also focus on all municipal elections held between 2001 and 2012. This is especially important for our analysis because the M5S became politically active at the local level a few years before entering the national stage. Finally, we will also look at participation in national referenda. According to the Italian constitution, referenda can only be used to abrogate existing laws (or part of them) and require a 50\% turnout quorum to be valid. Various referenda have been held over the past few years, on a variety of issues ranging from electoral rules to public management of water supply and nuclear energy, among others. These referenda, which are promoted by popular initiative, have been largely ignored, when not overtly boycotted, by mainstream parties (and mainstream media), and hence provide voters with a rather different, and relatively antiestablishment, opportunity for political participation.

\subsubsection{EMERGEnCE AND Rise of THE Five-Star Movement (M5S)}

In the most recent parliamentary elections, held in February 2013, the M5S emerged as the most voted party, obtaining $25.5 \%$ of the votes. This represented the best electoral performance for a party running for the first time in national elections in post-war Italy. Since the general perception is that the Internet was central to the emergence and political development of the M5S, it thus provides us with a unique opportunity to understand the impact of Internet on political participation, both online and offline. The M5S started in 2005 as a grassroots protest movement, and then consolidated into an organized political actor running for elections first at the local level, and finally at the national level.

Internet and social media are at the heart of the M5S organization and political activism, especially in light of its rejection of mainstream media, which M5S activists see as captured by powerful economic and political interests. A cornerstone of this organization is the blog that Beppe Grillo, the Movement's charismatic leader, created in January of 2005, from which most of M5S political initiatives have traditionally originated. Another is the online platform Meetup.com, which has been used 
by Beppe Grillo's supporters since 2005 to organize in thematic groups and coordinate their activities at the local level. ${ }^{8}$ The Meetup.com platform has represented the springboard for the later emergence of a decentralized bottom-up political movement that ultimately made the leap to the national stage.

In the first phase of the blog/Meetup experience, between 2005 and 2007, the initiatives promoted by Grillo and his supporters were primarily aimed at voicing widespread popular discontent with the lack of transparency and accountability in the Italian political system. Their criticism was directed against corruption, the misuse of public funds by political parties, the inadequacy of the electoral system, and the absence of legislation imposing both term limits on elected officials and the ineligibility of previously convicted politicians. ${ }^{9}$ Despite the considerable popular response they generated, these initiatives were largely ignored by mainstream politicians.

Grillo and his supporters then moved towards the creation of an active political movement to run in elections. This new phase begun in 2008, when Grillo announced on his website that he would endorse local groups of citizens willing to run for elections, particularly at the local level, as long as candidates subscribed to the movement's platform on a variety of issues (including free and universal broadband Internet access) and satisfied certain transparency requirements: no affiliation to any party, and no prior penal conviction. The endorsement would take the form of a quality certification "fivestar seal". 10

The first Five-Star-certified lists ran in municipal elections in 2008, in a handful of municipalities, and in Sicily's regional elections in that same year, with rather modest outcomes. Since then, the M5S has taken part in an increasing number of municipal and regional elections with increasing success. It elected its first mayor in 2010, and became the most voted party in Sicily's 2012 regional elections, before running for national elections in 2013.

Throughout this trajectory, the use of web-based social media and of the original network of local Meetup groups has remained absolutely central to the evolution and growing electoral success of

\footnotetext{
${ }^{8}$ The Meetup.com platform was created in 2001 in the US, to facilitate online networking of people sharing similar interests towards enabling them to meet in person. Howard Dean is understood to be the first prominent politician to use the Meetup.com platform on a large scale to coordinate his supporters, during the 2004 Democratic party primaries. As pointed out by Hindman (2009): 'New technology allowed Dean to create local, decentralized social networks from scratch." (Hindman, 2009, p. 32). Interestingly, it seems that most of the Dean campaign volunteers recruited through the Meetup.com platform had not been involved in previous electoral campaigns Hindman (2009).

${ }^{9}$ For example, in November 2005, Grillo's blog launched a fund-raising campaign aimed at financing the publishing of a list of previously convicted Italian MPs on the International Herald Tribune, in the context of the so-called "Clean Parliament Initiative". On September 8 2007, a campaign was launched in several Italian cities to collect the signatures required to propose three laws of popular initiative to Parliament, dealing with the ineligibility of convicted politicians, the imposition of a two-term limit for both national and local elected officials, and a reform of the electoral system. Overall, more than 300,000 signatures were collected in one day.

${ }^{10}$ The M5S refuses to be framed in the traditional left-right dimension, claiming to be "beyond" it. Indeed, some points of the M5S political platform (e.g., the emphasis on green energy or extended unemployment benefits) have clear roots in the tradition of leftist parties or the green wave started in western Europe in the 80s like the German Grünen (Pedrazzani and Pinto, 2013). At the same time, other parts of the M5S' program (e.g., the opposition to Roma immigration) seem closer to the positions of right-wing parties.
} 
M5S. Indeed, the selection of M5S national candidates has been carried out through online primary elections among M5S early activists. Furthermore, evidence on the presence of candidates from different parties on the web suggests that, despite the lack of financial resources on the same scale available to other parties, M5S candidates have been especially successful in communicating with potential voters through web-based platforms such as Youtube and social media such as Facebook, Twitter, Google+ and Foursquare (Mosca and Vaccari, 2013).

\section{DATA AND EMPIRICAL STRATEGY}

\subsection{DATA}

Electoral data at the municipal level for both local and parliamentary elections as well as for popular referenda are available from the Italian Ministry of Interior. The Italian administrative system includes 8,100 municipalities with a median area of $22 \mathrm{~km}^{2}$ and median population of 2,468 people; each municipality belongs to one of 110 provinces, and each province to one of 20 regions. ${ }^{11} \mathrm{We}$ focus on the balanced sample of 7,969 municipalities for which we have information for all of the parliamentary elections we consider. ${ }^{12}$ The data include information on eligible voters, turnout, and votes for individual parties and referendum questions. We focus, in particular, on the past five parliamentary elections, held respectively in 1996, 2001, 2006, 2008 and 2013, on the municipal elections held between 2001 and 2012, and on two series of referenda held respectively in 2009 and $2011 .^{13}$

Data on the Beppe Grillo/M5S Meetup groups were gathered directly from the Meetup.com platform, by applying a crawling procedure on the webpage of each group related to either Beppe Grillo or the M5S. For each group we collected the following information: date of formation, geographic location, number of members, and the date at which each member joined the group; when multiple groups are present in a given municipality, we consider the date at which the oldest group was formed.

Data on the availability of ADSL technology in Italian municipalities were provided by the "Osservatorio Banda Larga-Between," a joint-venture between the main Italian telecommunications operators, the Italian Ministry for Telecommunications and other private and public stakeholders. The data include information on the percentage of households with access to ADSL-based services in each Italian municipality between 2005 and 2011 on an asymmetric six-point scale, ranging from zero to 5 , corresponding to the following brackets: $0 \%, 1-50 \%, 51-75 \%, 76-85 \%, 86-95 \%$, and above $95 \% .{ }^{14}$ No data are available for previous years, and we set the measure to zero for year 2001 and before,

${ }^{11}$ When looking at parliamentary elections we exclude the region of Valle D'Aosta, since it adopted a different electoral system with respect to the one used in the other regions, starting with the 2001 elections. This means that we will have 109 provinces in our sample.

${ }^{12}$ Results are essentially unaltered if we consider all municipalities available in any given year.

${ }^{13}$ Three other series of popular referenda were held respectively in 2003, 2005 and 2006. Unfortunately municipal data on turnout in these referenda are not available from any source.

${ }^{14}$ Figure B.5 in Appendix B reports the distribution of ADSL coverage by year with the percentage of household with ADSL access increasing from grey (limited access) to black (full access). 
as an approximation of the very low levels of broadband penetration at the time (reported in Figure 1). Also, since our data on broadband access stops at the end of 2011, we attribute the 2011 data to election year 2013, a choice which naturally introduces some additional measurement error.

We choose to use data on broadband access, rather than penetration, first and foremost because the latter is obviously the result of endogenous individual decisions. That said, and very much as expected, the data show a clear positive link between broadband access and penetration at the regional level, the lowest level for which penetration data is available for Italy (see Figure B.6 in Appendix B). More specifically, we use the six-point scale as our main measure of broadband Internet exposure, and label it "Broadband Access".

However, we also experiment with alternative measures of broadband access, both for robustness and to better interpret the nature of our results. First, we use "Years Since Good Broadband", defined as the number of years since at least $50 \%$ of households in a municipality have ADSL access. The main advantage of this measure is that it allows for the possibility that the effect of the Internet accumulates over time; an important disadvantage, however, is that we are forced to consider 2005 as the first year of good broadband access for all municipalities that were covered up to that point, because that is the first year for which we data are available. This naturally adds considerable noise to this measure in the early years of our sample. On the other hand, the error introduced by attributing 2011 broadband access data to the 2013 observations should be less important when we consider this alternative measure.

In addition, we also use two dummy variables computed from the six-point scale: "Full Access", which takes the value of 1 if "Broadband Access" is equal to 5 (above 95\% access), and "Some Access", which takes the value of 1 if "Broadband Access" is greater than 0 . The use of these measures will facilitate interpretation, as they do not rely on the asymmetric scale, and will allow us to better understand what variation driving our results. Still, we keep "Broadband Access" as our main measure of interest, so as to not discard information.

Finally, information on additional socio-demographic controls, which we discuss below, is available from the Italian national statistical office (ISTAT). ${ }^{15}$

\subsection{EMPIRICAL SPECIFICATION AND IDENTIFICATION STRATEGY}

Following our discussion on the characteristics of the Italian broadband infrastructure, our identification strategy exploits the role played by the distance between the existing Central Office (CO) supplying voice services to a given municipality and the closest urban group exchanges (UGS). First of all, we rely on the fact that this distance represented the main determinant of the cost of supplying ADSL services in a municipality, given the technical need to deploy optical fiber connection between the municipality's CO and the closest UGS. As such, we would expect the distance to the closest UGS

\footnotetext{
${ }^{15}$ Descriptive statistics for all of our main variables can be found in Appendix Tables A.1-A.3.
} 
to affect the pattern of ADSL rollout across different municipalities. The clear negative relationship between distance to the closest UGS and broadband access (as of 2006) is depicted in Figure 3.

As pointed out before, the presence and the location of both the COs and UGSs precede the development (and even the existence) of broadband in Italy. This of course does not mean that their spatial distribution is random, and, in fact, the data reveal that UGSs are more likely to be located, for instance, in provincial capitals, and, more generally, in more densely populated and educated places. These are all characteristics that could be expected to correlate with our outcomes of interest in ways that could confound causal interpretation. We can go some way in addressing these confounding factors by exploiting the panel structure of our data and including municipality fixed effects; however, this evidently does not control for those factors that change over time.

To deal with this issue, our key source of variation will be the interaction between the distance from a municipality to the closest UGS and a dummy for the post-2001 period (i.e. after the introduction of broadband Internet). In essence, we implement a differences-in-differences approach, which has the important advantage of letting us use variation from a broad set of municipalities, thereby naturally enhancing the generalizability of our findings. As usual, our underlying identification assumption is that, whatever correlation existed between the distance to the closest UGS and relevant municipality characteristics, this did not change at the time of introduction of ADSL technology. In other words, we are identifying off of the change in the impact of distance on the outcomes of interest, under the assumption that any change in that impact occurs solely through the introduction of Internet.

This basic assumption justifies the following two-stage specification:

$$
\begin{gathered}
Y_{m, t}=\gamma \text { Broadband }_{m, t}+\beta X_{m, t}+\alpha_{m}+\tau_{t}+\varepsilon_{m, t} \\
\text { Broadband }_{m, t}=\phi\left(\text { Distance_UGS }_{m} \times \text { Post-2001 }\right)+\sigma X_{m, t}+\zeta_{m}+\theta_{t}+\eta_{m, t}
\end{gathered}
$$

where subscripts $m$ and $t$ indicate respectively municipality and electoral year, $Y$ represents the outcome of interest (e.g. turnout), $\alpha$ and $\zeta$ are sets of municipality fixed effects, $\tau$ and $\theta$ are year fixed effects, and $X$ encompasses a set of control variables that we discuss below. Broadband stands for one of the measures of broadband access described above. Distance_UGS is the (time-invariant) distance from a municipality's centroid to the closest UGS. We interact this variable with a dummy (Post2001) that takes the value of 1 for electoral years after 2001. This implies that the shift introduced by the availability of ADSL technology stays constant after its introduction, which seems consistent with the data. ${ }^{16}$

Our basic identification assumption will be violated if there are subjacent trends in our outcomes

\footnotetext{
${ }^{16}$ We also experiment with letting that impact vary with time, by setting $T=1$ for $2001, T=2$ for 2002 , and successively, and the basic results are consistent. However, if we exclude the pre-2001 period and focus on the later years only, the interaction between distance and time loses its power as a predictor of broadband access. This indicates that the shift introduced by ADSL availability was indeed a one-off.
} 
of interest that happen to correlate with factors that are in turn correlated with Distance_UGS. For instance, it could be the case that turnout evolved differentially in urban versus rural places around the time of the introduction of ADSL technology, for reasons unrelated to the Internet. To account for this possibility, we make use of a number of municipal socio-demographic characteristics available from the 2001 Census. Specifically, we include in $X$ the interaction of those characteristics with either a fourth-order polynomial in time, or with the Post-2001 dummy, or, finally, with election year fixed effects. This lets us control very flexibly for the possibility of differential time trends: the polynomial allows those trends to differ smoothly, the Post-2001 dummy considers the possibility of a break around the introduction of broadband, and the year fixed effects impose minimal structure. Hence, our identification strategy requires that there is no change in the correlation between distance to UGS and the outcomes of interest around the time of broadband introduction once we account for those demographic-related trends.

The set of demographic variables includes population, age structure (measured by the share of population aged 65 or more, and the share aged 20 to 34, i.e. old and young voters), and urbanization (measured on a 3-point scale according to the ISTAT classification). ${ }^{17}$ As shown in Appendix Table A.4, these variables are highly correlated with the initial diffusion of the internet, as was to be expected. What is more, Appendix Table A.5 shows that broadband internet access (as of 2006) is not correlated with our key dependent variable (turnout) once these demographic variables are accounted for. This suggests that controlling for them indeed helps us focus on the idiosyncratic component of the variation in that access, thus complementing the fixed effects strategy that controls for unobserved time-invariant municipality characteristics. For the sake of robustness, we also add a second set of demographic controls, namely education, number of firms per capita, and the distance to the closest provincial capital (capoluogo). Note in particular that, by including both urbanization and distance to provincial capital, we are controlling in multiple ways for the possibility that small, isolated towns, that are more likely to be far from a UGS, may have differential trends in our variables of interest, as compared with larger urban centers.

Finally, we also control for regional dummies interacted with the election-year dummies to account for any effect of unobservable regional factors that may vary over time. ${ }^{18}$ This allow us to further account for any pre-existing or underlying trends that could confound the causal interpretation of our estimated coefficients. In all regressions we cluster standard errors at the province level to allow for the possibility of correlated shocks within each of the 109 provinces in our sample.

\section{Broadband AcCess and Turnout in National Elections}

Our central question is: what is the effect of broadband internet access on political participation? We start by looking at turnout in Italian legislative elections (focusing on the lower House), comparing the

${ }^{17}$ As it turns out, the only variable that is available on a yearly basis at the municipality level is population, so we include that in all specifications as well.

${ }^{18}$ Similar results obtain if we use province dummies instead of region. 
two pre-broadband elections of 1996 and 2001 to the three post-broadband elections of 2006, 2008, and 2013. From an empirical perspective, looking at national elections has a major advantage in terms of data availability: for every election year we have information for all the roughly 8,000 municipalities. This greatly increases the effective sample size, and lets us take full advantage of the contrast between the pre- and post-broadband eras, while controlling for unobserved municipality characteristics. As emphasized in our conceptual discussion, the effect of the Internet on political engagement could potentially vary considerably over time; looking at multiple post-broadband elections, allows us to better examine the evolution of such effect.

\subsection{PRELIMINARY EVIDENCE}

We start by looking at the raw data. Figure 4 summarizes the evolution of the difference in turnout between those localities that would eventually be early-adopters of broadband internet and those that would turn out to lag in that respect. We can see rather clearly that, in the pre-broadband years of 1996 and 2001, the eventual early adopters display substantially higher turnout, consistent with the fact that these are, on average, more educated and densely populated localities. This difference is essentially unchanged between the two elections. However, the picture changes substantially after broadband is introduced: the gap in turnout drops considerably, consistent with a substantial negative initial effect of broadband access on turnout. However, it is also clear that, by 2013, the initial drop is partially reversed.

How does this pattern relate to our key source of variation? To see it most clearly, let us consider the distribution of municipalities according to distance to the closest UGS. Specifically, we take the bottom and top $5 \%$ of that distribution, which correspond respectively to a distance of less than $3 \mathrm{~km}$ and more than $30 \mathrm{~km}$ from the closest UGS; we may think about these sub-samples as roughly representing "treatment" and "control" groups in the natural experiment of broadband access induced by the structure of the pre-existing telecommunications network. ${ }^{19}$ These groups are very different in many dimensions, but it is nevertheless instructive to compare the evolution of turnout in each one of them. To this end, we estimate a a regression of turnout on election-year fixed effects, and take the average residual for each group as a measure of turnout relative to the national average for a given election year.

The results, plotted in Figure 5, depict a very clear drop in turnout between the last pre-broadband election (2001), and the first post-broadband election (2006) in the group more likely to have early ADSL coverage. No comparable break is apparent for the "control" group, which shows a modest uptick. This pattern helps validate our empirical strategy, suggesting that the reduction in the turnout difference detected in Figure 4 is overwhelmingly driven by the "treated" group, and confirming the

${ }^{19}$ The average "Broadband Access" scores of the two groups, as of 2006, were 4.6 and 1.6, respectively - the share of unconnected municipalities was then $1.5 \%$ and $57 \%$. Even by 2008 , one in four municipalities in the "control" group were still not connected, against less than $0.5 \%$ of the "treatment" group. 
absence of any discernible pre-existing trend in either group. ${ }^{20}$ Interestingly, we again see a partial reversal of the initial movement in 2013, with an uptick in turnout for the early adopters and a drop for the late adopters, which, by then, are much better connected than in previous elections years.

To examine how the change in electoral participation relates to distance from the closest UGS in the overall sample of municipalities, it is also instructive to consider the coefficients from a reduced-form regression of turnout on distance estimated separately for each election year. Figure 6 reports the coefficients obtained from estimating such a regression including the full set of controls described and both province and local labor market (SLL) fixed effects. ${ }^{21}$ Consistent with the evidence shown above, it is clear that, prior to the advent of broadband, there was a stable and statistically significant relationship between turnout and distance, with more distant places displaying lower levels of turnout. However, this relationship essentially disappears upon the introduction of broadband in, before reappearing in 2013 .

Taken together, this preliminary evidence suggests a substantial negative effect of broadband access on turnout upon the introduction of the technology, followed by a partial reversal in later years. In what follows we show that this conclusion very much survives further scrutiny of the data.

\section{2. “SHORT-RUN" EFFECTS: 2006/2008}

We start by examining the more immediate impact of broadband introduction, by comparing the last two pre-broadband elections, held in 1996 and 2001, and the first two post-broadband ones, held in 2006 and 2008. In Table 2 we implement the two-stage specification in (1) and (2) excluding 2013 from the sample. Column 1 reports the basic OLS results controlling for population and for regionyear and municipality fixed effects. The coefficient on broadband access is negative and statistically significant suggesting that the advent of high-speed Internet was associated with lower turnout. The estimated effect is, however, relatively small: going from zero to full broadband access would correspond to a decline in turnout of about 2 p.p. (relative to an average turnout above $80 \%$ in 1996 and 2001).

We then instrument broadband access with the interaction between distance to the closest UGS and the post-2001 dummy. Again, we find a negative and statistically significant effect (column 2). Quite strikingly, the effect is a lot larger than in the baseline OLS specification: going from no zero full broadband coverage is now associated with a decrease in turnout of almost 13 p.p. However, the estimated effect drops substantially, to 7 p.p., when we control for the smooth trends (column 3); this

${ }^{20}$ The only demographic variable for which we can build a similar plot is population, which is available on a yearly basis. Figure A.1 in the Appendix shows that there seems to be smooth opposing trends in the two groups, but no breaks are apparent between the pre- and post-broadband periods. We will return to this when discussing the regression results.

${ }^{21}$ Local labor markets (SLL) are commuting areas designated by the Italian statistical office as groups of municipalities that are contiguous, and geographically and statistically comparable. The country is divided in 658 SLLs, with each SLL comprising, on average, just over ten municipalities per SLL. 
suggests that it is indeed important to control for differential trends in population, age structure, and urbanization.

Columns 4 to 6 show that this result is rather robust, qualitatively and quantitatively. First, the second set of demographic controls does not affect the coefficient; if anything, the absolute value seems to go up. In addition, the coefficient barely budges when we consider the interactions of demographics with the Post-2001 dummy or with election year fixed effects, although it is estimated with a bit less precision. These results document a robust and substantial negative effect of broadband Internet on voter turnout in the immediate aftermath of its introduction.

In Table 3 we further test the robustness of this finding. As our baseline specification, we use the one with the interaction between the first set of demographics and a fourth-order time polynomial (as in column 3 of Table 2), since the inclusion of additional controls does not affect the estimated coefficient. We first deal with the concern that the results could be driven by the contrast between large cities, more likely to be close to a UGS, and small isolated towns. While we have controlled throughout for the possibility of different trends according to the degree of urbanization, we then re-estimate our main specification limiting our sample respectively to non-urban municipalities, as designated by the ISTAT classification (column 1), and to municipalities without their own UGS (column 2). In both cases the coefficient on broadband access remains virtually unchanged.

To further explore the nature of the effect, we then consider different measures of broadband access. In column 3 we use "Years Since Good Broadband" and find a similarly negative effect. In this case, however, the first stage becomes considerably weaker, likely due to measurement error which, as discussed in Section 4.1, is particularly important for this measure in the early years of broadband diffusion. In columns 4 and 5 we then consider our two alternative dummy variables. Quite remarkably, the coefficients are almost exactly the same for either the "Full Access" and the "Some Access" dummy, and correspond quantitatively to essentially the same effect estimated for our baseline "Broadband Access" measure (i.e. around 7 p.p.). This result suggests that the relevant variation in our data is coming from the comparison between municipalities with no access (0) and those with full access (5), rather than from municipalities with partial access (i.e. between 1 and 4) which, in fact, only represent about $8 \%$ of our sample. This is consistent with the technological fact that the bulk of the cost of broadband provision is to reach a given locality: once connected, it is relatively inexpensive to provide it with full coverage.

In column 6, we attempt to deal in another way with the possibility that we could be picking up some underlying trend in turnout that just happened to be correlated with the diffusion of broadband. To do so, we run "placebo" IV specifications for the pre-ADSL election years of 1996 and 2001 only, assuming that the patterns of internet access observed in 2006 had been present in 2001. Reassuringly, we see no impact of this fictitious episode of introduction of broadband internet, a result which further supports the view that our findings are not driven by pre-existing trends.

Finally, we also check the results against demographic patterns. For instance, it would be surprising, 
and concerning, if the effect of broadband was coming primarily largely from municipalities with large senior populations, which would presumably be less exposed to the Internet. In columns (7) and (8) we show that the effect is indeed significantly larger for municipalities with fewer elderly people (i.e. in the bottom quartile of the distribution of the share of over-65-years-old), while there is no effect for municipalities with older population (i.e. in the top quartile).

All in all, our estimates point very consistently to an immediate negative effect of the diffusion of broadband on turnout, of the order of about 7 p.p. To get a better sense of what this magnitude implies, following DellaVigna and Kaplan (2007) and DellaVigna and Gentzkow (2010), we compute the corresponding "persuasion rate". The persuasion rate is defined as the share of individuals who did change their behavior, out of those who could have changed it to begin with. In our case, the change in behavior is from voting to not voting, so the set of potentially affected individuals is the set of those who turned out in 2001, corresponding to $79.8 \%$ of the total population. Considering that, in $2008,45 \%$ of the Italian population reported having broadband internet (ISTAT), out of the $93 \%$ of the population living in connected municipalities, and assuming that voters and non-voters are equally likely to have broadband, we take that out of 100 Italians approximately $39(100 * 0.798 * 0.45 / 0.93)$ could potentially be affected by the broadband "treatment". It follows that going from zero to full access would imply a persuasion rate of approximately $18(100 * 5 * 0.0145 / 0.39)$. In other words, eighteen percent of the "treated" individuals were actually persuaded to abstain. This is very much within the range of the persuasion rates (between 4 and 20) reported by DellaVigna and Gentzkow (2010) in their survey of studies on the effect of media on voting behavior.

\section{3. “LONG-RUN” EFFECTS: 2013}

We now turn to the effects of broadband access as seen from the vantage point of the 2013 elections. To do so, we compare the 2013 elections with the pre-broadband period (1996 and 2001), leaving aside the elections of 2006 and 2008.

The results are shown in Table 4. In column 1 we estimate our preferred specification, with the interaction between demographics and the time polynomial. The coefficient of interest is now statistically insignificant and, although the absolute value is in line with what found in Table 2, the sign of the coefficient is now positive. Hence, we find no evidence of a negative effect such as that documented for the immediate aftermath of broadband introduction. In line with the preliminary evidence presented above, this result confirms that the immediate impact of broadband on turnout had been largely reversed by $2013 .^{22}$

The remainder of Table 4 further reinforces this message. First of all, we deal with the concern that, by 2013 , the places still left without broadband access might be quite peculiar (in fact the first-stage F-

${ }^{22}$ In principle, a possible concern for our identification strategy as we reach 2013 may be posed by the presence of mobile broadband in areas where ADSL is not available. However, as explained in Appendix B, the characteristics of the mobile broadband infrastructure, its coverage and the use of mobile broadband in Italy all point to the conclusion that this is not an issue for our analysis. 
statistic is considerably smaller than in the previous tables, indicating that distance to the closest UGS is less predictive of differences in broadband access by 2013.) In this respect, it is reassuring that, when estimating the effect only on the sample of non-urban municipalities (column 2), the results are very similar. Similarly, the picture does not change in columns 3 and 4 when we use "Years Since Good Broadband" as measure of broadband access, a variable for which there is still a lot of variation even as of 2013. It is also worth noting that the measurement error for this variable seems less problematic in 2013, as illustrated by the fact that the first stage F-statistic is considerably larger than in Table 2. Finally, the results remain unchanged in columns 5 and 6 when using the dummies for "Full Access" and "Some Access" as alternative measures of Internet coverage.

In sum, our results show quite clearly that the effect of the Internet varied considerably over time: while in the first years of Internet diffusion broadband had a substantial negative effect on turnout in national elections, this tendency was at least partly reversed in later years. This pattern raises our confidence in the identification strategy: indeed, any story that would ascribe the documented effect to unrelated spurious trends should also explain this sharp reversal, which does not seem obvious.

\subsection{Full SAMPLE}

For the sake of completeness, we also present the results of our estimation for the full sample of elections, i.e. from 1996 to 2013 (Table 5). The pattern that emerges in columns 1 and 2 is quite similar to what found in Table 2, with a negative, statistically significant coefficient that is considerably larger for the IV specification (columns 1 and 2). This similarity is not surprising, since most of the variation in the full sample comes from those initial years of the sample. The results do not change much in columns 3 and 4 when we include interactions between demographic characteristics and a fourth-order time polynomial to account for smooth unobservable trends.

Things look quite different, however, when we allow for the possibility of sharper trends, either by interacting the demographics with the Post-2001 dummy (column 5) or with year fixed effects (column 6). In this case, the estimated effect of broadband on turnout is not statistically significant and much smaller in magnitude, estimated around 3 p.p. for going from no coverage to full coverage, with the first stage also suffering considerably. It thus seems that the reversal pattern uncovered in the previous analysis is being picked up as sharp trends in the data, thus confounding our empirical strategy. By looking at these results, one might have concluded that the evidence of any effect of broadband on electoral turnout is weak, when in fact there was a lot going on in the meantime.

\section{Broadband Access and Political Participation: Elucidating the MECHANISM}

We have thus established that the impact of broadband Internet on political participation in Italian elections varied substantially over time. We now turn to the task of trying to elucidate what were the 
driving forces behind this nuanced pattern.

\subsection{WINNERS AND LOSERS}

In line with our conceptual discussion, we want to understand what categories of voters were more likely to drop out as a result of the introduction of broadband, since this would help elucidate the incentives faced by both established political forces and potential newcomers. One way to do so is to look at what parties and coalitions were more affected by the drop in turnout in early post-broadband national elections. In fact, to the extent that supporters of different political forces differ with respect to their level of political engagement and political information, documenting a differential impact of Internet on voters of different parties could be extremely instructive. ${ }^{23}$

In Table 6 we distinguish between the mainstream center-right and center-left coalitions, and the "outsiders", that is, those political forces that come into elections with very little chance of affecting political balance. ${ }^{24}$ We then compare the results obtained by these three groups of parties in the elections of 2001 and 2008. We choose these years because in the 1996 elections the coalitions were very different, and in 2006 different electoral rules greatly increased the incentive of smaller parties to join the main coalitions; as a result, the definition of mainstream coalitions are very different in these elections.

The first panel shows the coefficients on "Broadband Access" (with the full IV specification), using as dependent variable the vote shares of each of the three groups. The results suggest that the mainstream center-right and, especially, the center-left coalitions gained modestly at the expense of the outsider parties. However, this initial conclusion is very much qualified by the results in the second panel where, instead of using as dependent variable the vote share relative to the total number of votes cast, we use the share relative to the total number of eligible voters (which is very much stable over time); this allows us to control for the negative impact on turnout documented above. This second set of results suggest that what looked like a gain for the two mainstream coalitions, was not coming from an increase in electoral consensus, but, rather, from a stable electoral consensus accounting for a larger share of a smaller pool of total votes. In terms of changes in actual electoral performance, the

${ }^{23}$ In addition, those patterns are interesting in and of themselves: as an across-the-board drop in turnout could have very different political implications from a scenario in which different parties or coalitions are affected differently. This can obviously speak to the question of whether the internet has operated as a polarizing force or not, on which there has been much debate and relatively conflicting evidence (Sunstein, 2009; Hindman, 2009; Gentzkow and Shapiro, 2011)

${ }^{24}$ Appendix Table A.6 reports the breakdown of the results for each of the main parties in the two mainstream coalitions, and for each of the main groups of outsider parties. For the definitions of coalitions, see Appendix Table A.7. The Italian system has a large number of parties, with new ones forming and old ones merging and dissolving very often; by the same token, the main coalitions are led by the same forces over this period, but their membership varies drastically across election cycles. For each election, we take the main center-right and center-left coalitions, and define all parties that do not belong to either as outsiders, with the exceptions of the M5S and Monti coalition in 2013. Table A.8 describes how the different party labels in Table A.6 map onto different parties in different elections, because of mergers. 
most distinctive impact of the introduction of broadband is certainly the negative impact on votes for outsider parties. ${ }^{25}$

The fact that those who seem to drop out are the supporters of outsider parties - which include those more at the extremes of the ideological spectrum, such as the unreformed Communists - suggests that the fall in turnout is due to more subtle reasons than a simple reduction in the consumption of political information. To further explore this aspect, we use data from the Italian National Election Study (ITANES), a series of electoral surveys conducted on a representative sample of the Italian population in coincidence with national parliamentary elections. We focus in particular on the 2001 wave, which interviewed 3,209 individuals and included various questions on self-reported voting choice, political participation, and media consumption. Based on this information we construct measures of "Interest in Politics", "Political Activism", and "Political Information", and look at differences along these dimensions between voters of different parties and coalitions. ${ }^{26}$

Figure 7 presents the results, comparing the averages for voters who reported to have voted for either of the mainstream coalitions, and for outsider parties (variables are standardized, so that magnitudes correspond to standard deviations of each of the variables). The comparison suggests that voters of outsider parties are among the most interested in and informed about politics, and certainly the most politically active. ${ }^{27}$ This evidence seems hard to reconcile with the view that the effect of broadband would be operating through demobilization induced by reduced information since those voters are unlikely to be the ones disproportionately switching into online entertainment. All in all, this suggests that the depressing effect of broadband internet on turnout in national elections was driven by the disengagement of individuals who were already disappointed with mainstream politics. If that is the case, the initial impact of broadband constituted an opportunity for political entrepreneurs who could target that disenchanted audience.

This message is reinforced by the results on the electoral performance of different parties and coalitions in 2013, reported in Table 7, estimated using votes per eligible voters as dependent variable. ${ }^{28}$ In columns 1 and 2 we see that old-fashioned mainstream coalitions and outsider parties did not gain from the reversal in the initial drop in turnout. Instead, increased turnout benefited new political forces, and especially the M5S (column 3). The strong positive effect of longer exposure to broadband on support for M5S, in particular, is consistent with the fact that Grillo's movement relied crucially on the Internet for its organization and, later, for its campaign effort. Interestingly, the M5S was not the only one to benefit from the Internet's mobilization potential. First, another new "web-friendly" political movement, "Fare per Fermare il Declino" (henceforth Fare), was also able to leverage the

\footnotetext{
25 This effect was particularly pronounced on the extreme left, as shown in Appendix Table A.6.

26 More information on how these variables were constructed is reported in the notes to Figure 7.

27 The party breakdown (available upon request) shows that the unreformed Communists, which represent the bulk of outsider voters in 2001, score particularly high in all three dimensions.

${ }^{28}$ Note that we attribute zeroes to the parties or movements that were not on the ballot in 2001, such as the M5S. This means that the identification in those cases is less clean, since it is coming essentially from the cross-sectional variation.
} 
effect of the Internet, though to a much more limited extent than the M5S (column 4). ${ }^{29}$ This further supports the view that the supply-side of the political system did react to the initial shock represented by the diffusion of high-speed internet and the subsequent emergence of a pool of "connected" but disenchanted individuals. We also find a relatively mild positive effect in favor of the new centrist force led by former prime minister Mario Monti; this results suggests that, more generally, Internet may have offered greater visibility to new comers than traditional media. ${ }^{30}$

In sum, the evidence presented suggests quite clearly that the initial negative effect of broadband internet on political participation in national elections was driven by individuals who were relatively engaged and informed about politics to begin with, but disenchanted with mainstream political offerings. By the same token, its reversal benefited new political forces which emerged presumably in response to the incentives posed by that initial effect.

\subsection{Other Forms of Participation: Online Platforms and the Rise of the FIVE-STAR MOVEMENT (M5S)}

We now turn to the question of what happened between the initial negative impact of broadband on turnout and its reversal. Specifically, can we find evidence that those who presumably dropped out of the mainstream political process may have remained politically active in other ways? Can we establish a link between those other ways and the eventual reversal? For that we look at other forms of political engagement that were going on in the intervening years, both online and offline, beyond mainstream national elections. Fortunately, the Italian political system, and its evolution in recent years, offers a number of windows into those different patterns.

\subsubsection{OnLine ACTIVITY AND THE M5S}

We start by looking at the effects of broadband access on electoral participation on a notable measure of online political activity: the evolution of the local grassroots protest groups inspired by Beppe Grillo on the online media platform Meetup.com. As discussed in Section 3.2.1, these groups constituted an important springboard in the expansion of the M5S, and in the eventual creation of M5Saffiliated electoral lists at the local level. It is not unreasonable to expect that the presence of these online protest groups would be enhanced by the diffusion of broadband internet - although one may wonder whether the disengagement opportunities offered by the internet, in the form of entertainment and different kinds of information, could negate that impulse.

${ }^{29}$ This movement was co-founded by a group of US-based academic economists. Most importantly, similarly to the M5S, it also exploited a blog as its springboard (namely, noiseFromAmerika.org, founded in 2006). However, the party suffered with a political scandal regarding the qualification of its political leader just before the elections, which naturally detracted from its performance. Its average share of votes was a mere $0.7 \%$, though it did get a significant share (up to $29 \%$ ) in a few localities.

${ }^{30}$ The Monti-led party could also be considered, to a lesser extent, an Internet-savvy movement. Indeed, Monti announced his intention to actively enter into the political arena on Twitter on December 26, 2012, and made extensive use of this platform, reaching in a couple of months more than 240,000 followers. 
To check for that, we construct a novel and comprehensive data set with information on the formation and membership of all local Meetup.com groups associated with the Beppe Grillo-led protest movement, which would eventually coalesce into the M5S. Specifically, for each municipality, we know whether, by 2012, one such group existed and, if so, the date at which it was originally created. Unfortunately, this means that we cannot use the time variation induced by the pre- vs. post-2001 breakdown. We thus have to focus on the variation across municipalities - hence excluding the municipality fixed effects and instrumenting Broadband ${ }_{m, t}$ using Distance_UGS $S_{m}$. As a result, the identification here is not as clean as when we can actually use the time variation within municipalities. To improve on that, we include both province and SLL fixed effects - hence identifying the effect from comparing municipalities within a very small area - and control for a range of municipal geographic and demographic characteristics. ${ }^{31}$ Our identification assumption would now have to be more stringent than before, requiring that the distribution of UGS within provinces and SLLs is as good as random, once we control for these characteristics. In light of this, we will refrain from pushing any causal interpretation of our estimated coefficients.

In addition, we also have information on the number of members of Meetup.com groups between 2005 and 2012 across the entire sample of Italian municipalities (we normalize membership in each municipality by 1,000 inhabitants). ${ }^{32}$ In this case there is time variation, and we can set the number at zero for the pre-broadband period of 2001. Still, the relevant variation is again coming from the post-broadband period only, and caution is still needed in interpreting the results.

Table 8 reports the results, using IV specifications. The first column uses as dependent variable the time since the creation of the first local group, as of 2012, to examine whether broadband access is associated with earlier group formation. The results confirm that in municipalities that had earlier access to broadband internet indeed groups tended to form earlier. In column 2 we then look at the panel variation in membership. We see that these groups also tended to have more members in places where broadband arrived earlier.

We should emphasize that, while this pattern is not exactly surprising, it is not as obvious as it might appear. Indeed, there is no deterministic relationship between broadband access and an increase in online participation in political activities. That is, the idea that broadband access leads individuals to participate online even in this specific type of activity is a hypothesis rather than a fact. Our

${ }^{31}$ Demographic characteristics include: education (\% population with a bachelor degree), age structure (\% population under 25 and \% population over 65), and number of firms per capita. Geographic controls include: distance from closest provincial capital, altimetric zone, dummy for mountainous area, dummy for coastal municipality, distance of the municipality's centroid from the coast, area, and terrain ruggedness index.

${ }^{32}$ We should stress that it is possible for an individual to be a member of multiple local groups, including in localities other than the one where she lives. To the extent that there exists an effect of broadband access on the existence of local groups, this possibility of multiple membership would magnify the difference between localities with extensive and limited access; we would argue that this magnified effect corresponds to the true impact of broadband access. In any event, the data on the date of formation of the groups should not be affected by multiple membership. 
results provide support to this hypothesis by showing that the use of online platforms for political mobilization is indeed related to the diffusion of broadband internet access.

Most importantly, in light of the connection between these online groups and the creation and expansion of the M5S movement, the results in Table 8 immediately beg the question of whether the diffusion of broadband access impacted the performance of that movement, once it started taking part in the electoral process. This would provide direct evidence that the kind of political entrepreneurship exemplified by the M5S indeed eventually developed the ability to translate the new mobilization tools into electoral participation and results.

For that we look at data on local elections. Municipal elections in Italy take place typically every five years, in staggered fashion so that every year has some elections taking place; we consider elections between 2001 and 2012, leaving aside the elections between 2002 and 2004, because the data on ADSL penetration is unavailable for those years.

Table 9 displays the results. In column 1 we see that municipalities with better access to broadband were more likely to have the M5S on the ballot, consistent with the idea that the creation of local Meetup.com groups translated into an M5S electoral presence at the local level. Note that, as we focus on more recent years, the fact that our ADSL coverage data goes only up until 2011 leads us to drop a lot of useful information from 2012. In light of that, we also show a specification with "Years Since Good Broadband" as our key independent variable, which lets us include those 2012 elections (column 2). ${ }^{33}$ Finally, in columns 3 and 4 we estimate the same two specifications using as dependent variable the share of votes obtained by M5S candidates (as a share of eligible voters); consistent with the previous findings, these results confirm that, in places with stronger and earlier broadband diffusion, M5S candidates' electoral performance was significantly better. ${ }^{34}$

The evidence presented suggest that the emergence of new political forces - likely in tandem with the evolution of the Internet itself, with the rise of social media and user-generated content - may have substantially changed the effect of broadband access on political engagement. Still, the empirical variation that underlies these results is unavoidably narrow, coming from a small and select group of places: the number of municipalities with the M5S on the ballot is rather small, and they tend to be relatively large in terms of population. As such, the variation is coming from a small and select group of places, and again we cannot control for unobservable characteristics at the municipal level.

33 The number of municipalities with M5S presence is 17 (2008), 51 (2009), 11 (2010), 78 (2011), and 103 (2012); the number of elections was $610,4284,1072,1338$, and 1006, respectively. The measure of years of good broadband coverage includes some inevitable additional measurement error for 2012.

${ }^{34}$ As for the impact of broadband on turnout in municipal elections, we find no robust result. Note that here we have variation coming from a small number of municipalities, since most localities did not have more than one election in the years of our sample (2001 and 2005-2011). This means that our coefficient is rather imprecisely estimated, and the first-stage relationship is much weaker than was the case in Table 2. 


\subsubsection{REFERENDA}

The M5S results are an indication that the diffusion of broadband internet did not have a simple negative effect on political participation. In fact, the idea that it actually had a positive impact on other forms of engagement is further bolstered by looking at participation in popular referenda referenda. As discussed in Section - , referenda have a peculiar role in Italian politics, as they can be called without the concurrence - and often under the active hostility - of mainstream parties. As such, they are often viewed as a form of political engagement at the margins of the mainstream political process. We have data on the referenda held in 2009 and 2011, both of which were, in fact, either ignored or opposed by mainstream parties and traditional media alike. This means that, once again, we cannot use the time variation induced by the pre- vs. post-2001 breakdown; hence, as for the municipal elections, we instrument Broadband ${ }_{m, t}$ using Distance_UGS $S_{m}$, include province and SLL fixed effects, demographic and geographic municipal controls, and cluster standard errors at the province level. We present the results separately for the 2009 and the 2011 referenda (similar results are obtained if we pool data for the two years together and include year fixed effects).

The results, for both the OLS and the IV specifications, are reported in Table 10. What we see is a strikingly different pattern relative to the national elections: a statistically significant positive association between broadband diffusion and turnout.

We cannot directly compare magnitudes with the coefficients in Table 2, not only because we cannot replicate our original identification strategy, but also because turnout in referenda is, of course, of a peculiar nature; indeed, minimum turnout requirements for enactment naturally imply that abstention essentially counts as a "No" vote. However, as noted above, this means that the mainstream parties, particularly the center-right coalition, were in many cases actively trying to keep turnout low. The positive association with turnout thus suggests that the internet had a rather damaging effect on the support for the mainstream parties (and especially the center-right) when it comes to the referenda, in a very different direction than what found for the national elections.

\section{DISCUSSION}

\subsection{INTERPRETING THE ITALIAN EVIDENCE}

The main takeaway from our results is that the impact of broadband Internet was rather nuanced. In particular, it varied across different forms of political participation and, quite crucially, also over time, consistent with the demand and supply sides of politics reacting endogenously to the increasing challenges and opportunities posed by the diffusion of the new medium.

We have documented that, at first, the introduction of broadband Internet across Italian municipalities was associated with a decline in political participation in the form of electoral turnout in national parliamentary elections. Our conceptual framework suggests, however, that this should be best interpreted as merely the immediate, partial-equilibrium effect of the change in media technology. Indeed, 
the initial drop in electoral participation was counteracted by rather distinct effects on other forms of political engagement, both online and offline. First, we provide evidence that early access to the Internet facilitated the emergence and expansion of local grassroots online protest groups. Second, it was also positively associated with higher turnout in popular referenda, which are largely boycotted by mainstream parties and tend to have a very distinct, more anti-establishment flavor than parliamentary elections. This pattern suggests that, while the Internet may have operated in the short run as a "demobilizing" force with regard to participation in mainstream elections, the same was not necessarily the case for political engagement more broadly.

What is more, our findings document how these new forms of mobilization seem to have eventually fed back into the mainstream electoral process. This process is exemplified most clearly by the emergence of the M5S, which, to a large extent, grew out of those local online groups and, in due course, turned into a potent electoral force. Our results show that, once it started competing in elections, the M5S was able to leverage the expansion of broadband access into better outcomes - as was the case, to a lesser extent, with other web-friendly newcomers. Their success strongly suggests that the initial demobilization, coupled with the possibilities offered by the new media platform, presented an opportunity that new, Internet-savvy political entrepreneurs were able to seize to enhance mobilization. Once this supply-side reaction had taken place, the initial negative effect on parliamentary election turnout was largely reversed.

This pattern is very much consistent with the exit, voice, loyalty framework discussed in Section 2. This is first underscored by the fact that it was the outsider parties, whose supporters one would have deemed more likely to exit, that essentially lost voters in the immediate aftermath of the introduction of broadband. In addition, the M5S, and to a lesser extent other similar forces, encapsulate the Internet's potential to transition from exit device to a novel source of voice within mainstream politics. These were typically movements that initially emerged outside and in explicit repudiation of mainstream politics, and that eventually gravitated toward taking part in it. In that sense, this constitutes another mechanism for what Hirschman called the "influence and power that come from "having nowhere to go" (1970, p.73): disenchanted voters opting for exit from mainstream politics became the driving force of a political movement that eventually punished the political forces that had disaffected them, through that movement's strong impact on mainstream politics.

In fact, it is rather clear from the survey evidence that the M5S has fished into the pool of demobilized voters. People who did not vote in the 2008 national elections are largely overrepresented among M5S voters compared to other parties: one out of seven people who voted for the M5S in 2012 local elections reported to have abstained in the 2008 parliamentary elections; the overall figure is only one out of fifteen (Pedrazzani and Pinto, 2013). 


\subsection{Alternative Mechanisms}

There could also be alternative interpretations for these demand-side movements, beyond the role of disenchantment. The initial drop in turnout, for instance, is evidently consistent with the existing literature on the effects of new media technologies, which has underlined how they may sometimes have negative effects on political participation. The usual explanation is related to the potential crowdingout of the consumption of existing media sources that placed a greater weight on relevant political information. The pool of demobilized voters surely contained many purely apathetic citizens, likely to tune out of political information when given the chance.

There is strong evidence, however, that the initial demobilization was indeed associated with disenchantment rather than pure apathy. First, we have documented that the drop in turnout was mostly linked to supporters of outsider parties, and unreformed Communists in particular, who tend to report relatively high levels of interest in politics and news consumption. Second, a pure apathy story would not lead us to expect other forms of participation to be enhanced by the Internet, as found in the data.

Additional evidence in that regard comes from looking at the socio-demographic characteristics of M5S voters. They typically have a medium-to-high level of instruction, and are generally wellinformed about politics (Pedrazzani and Pinto, 2013). Rather unsurprisingly, M5S voters were also heavy Internet users: $80 \%$ of M5S voters access the Internet and $42 \%$ use it as their main source of news (compared with a population average of $61 \%$ and $26 \%$, respectively). They are also more likely to express political opinions on websites or social media, and to visit websites of party or candidates (Mosca and Vaccari, 2013). In sum, these are to a large extent "people who have resources to be active and the willingness to do it but that find high barriers to entry into the traditional channels of political participation" (Passarelli, Tronconi, and Tuorto, 2013, p.130); people whose electoral abstention seems to be driven by protest rather than apathy (Tuorto, 2006).

Their anti-establishment profile is also apparent from direct survey evidence that M5S voters are more prone to opining that voting is useless, and that political parties are not necessary in a democracy. It is also supported by the evidence we find of a positive impact of broadband internet on political participation in the context of direct democracy: since the national referenda analyzed have been largely ignored or boycotted by mainstream political parties, that positive impact is likely to have involved voters dissatisfied with mainstream politics.

At the same time, the coordinating role of the Internet might also have been complemented by an informational one, thus amplifying its effects. For example, Bailard (2012) shows that, in a weaklyinstitutionalized environment, the Internet may also foster disenchantment, by increasing the citizens' level of information about an electoral system perceived as disreputable. By the same token, Chong, De la O, Karlan, and Wantchekon (2012) point out that an exogenous increase in the level of information about incumbent politicians' misbehavior may translate into lower levels of electoral participation. Hence, in a political system widely perceived as dysfunctional, such as that of Italy in the 2000s, Internet may have also boosted the short-run exit (and then its long-run conversion into voice) 
via an information channel.

\subsection{EXTERNAL VALIDITY}

A final question is whether we should expect the pattern we have detected in the case of Italy to be repeated in other contexts. There is good reason to think this could be the case.

Our conceptual framework suggests that the reversal should be expected once two main ingredients combine. First, the presence of a strong contingent of citizens who are dissatisfied with mainstream political forces, but not disengaged from politics in general. This phenomenon seems rather widespread, judging by recent trends observed in other countries. In particular, over recent decades voter turnout has decreased in many advanced democracies (Franklin, 2004) - a process that, many have argued, has been accompanied by an increase in the extent of public dissatisfaction with the performance and institutions of representative democracy (Pharr, Putnam, and Dalton, 2000; Dalton, 2004). The second ingredient is the fact that the Internet is a mobilization and coordination platform with relatively low barriers to entry, which is obviously not specific to the Italian case either. While the first ingredient implies that there will be an incentive for political entrepreneurs to jump into the electoral arena, the second one ensures that they will have an effective tool for doing that.

While more evidence is certainly in order, there are examples from other countries which seem prima facie compatible with this logic. For example, in the US, Howard Dean, Barack Obama and the Tea Party all represent underdogs who fished into different pools of voters who were disenchanted with mainstream politics, and who have used Internet as a coordination device to mobilize them. ${ }^{35}$ Similar examples from other countries may include the so-called "pirate parties" (Scandinavia, Germany), Yesh Atid (Israel), Alexei Navalny (Russia) and Rede Sustentabilidade (Brazil), with different degrees of success in influencing mainstream elections.

These examples also make clear that the aforementioned ingredients are likely to interact with institutional characteristics, so that specific patterns will differ depending on context. For instance, in a two-party system like the US, with very high barriers for third-party candidates, the role of the Internet in helping newcoming political entrepreneurs seems to have taken place within mainstream parties (via primary elections). This is rather different from what happened in Italy, with its relatively open proportional-representation system. As another example, in a relatively authoritarian regime in which one party exerts overwhelming influence over pre-existing media, the Internet might represent the only news source available for alternative points of view (see Miner, 2012, for the case of Malaysia). ${ }^{36}$ In this more fragile institutional context, the informative role of the Internet as a source of news is likely to have a more relevant impact. The role of such institutional features on the specific timing and shape of the effect of the Internet on political participation is an exciting avenue for future research.

\footnotetext{
${ }^{35}$ For some evidence in the case of the US, see Larcinese and Miner (2012) and Jaber (2013).

${ }^{36}$ Berlusconi's influence notwithstanding, this was not exactly the case in Italy (Durante and Knight (2012)).
} 


\section{REFERENCES}

AGCOM (2008-2012): “Annual Reports,” .

— (2011): "Volume di Sintesi: Infrastrutture e Servizi di Banda Larga e Ultralarga (ISBUL),” .

- (2012): "Osservatorio Trimestrale sulle Telecomunicazioni,".

Agenda Digitale Italiana (2013): "Piano Nazionale per la Banda Larga,” .

Anderson, S. P., And J. McLaren (2012): "Media Mergers and Media Bias with Rational Consumers," Journal of the European Economic Association, 4(10), 831-859.

Anduiza, E., M. Cantijoch, And A. Gallego (2009): "Political participation and the Internet: A field essay," Information, Communication \& Society, 12(6), 860-878.

BAILARD, C. S. (2012): “A Field Experiment on the Internet's Effect in an African Election: Savvier Citizens, Disaffected Voters, or Both?," Journal of Communication, 62(2), 330-344.

Besley, T., AND A. PRAT (2006): "Handcuffs for the Grabbing Hand? Media Capture and Government Accountability," American Economic Review, 96(3), 720-736.

Between (2006): “Il Punto sulla Banda Larga in Italia,” .

(2008): "Analisi sulle determinanti del processo di sviluppo della banda larga. Rapporto finale," .

(2010): "Italian Broadband Quality Index," .

Bordignon, F., AND L. CECCARINI (2013): "Five Stars and a Cricket. Beppe Grillo Shakes Italian Politics," South European Society and Politics, (forthcoming), 1-23.

Campante, F. R., And D. A. Hojman (2013): "Media and polarization: Evidence from the introduction of broadcast TV in the United States," Journal of Public Economics, 100(0), 79 - 92.

CASTAnheira, M. (2003): "Why vote for losers?," Journal of the European Economic Association, $1(5), 1207-1238$.

Chong, A., A. De la O, D. Karlan, And L. WantcheKon (2012): "Looking Beyond the Incumbent: The Effects of Exposing Corruption on Electoral Outcomes.," CEPR Discussion paper 8790 .

Ciapanna, E., And D. Sabbatini (2008): "La banda larga in Italia," Questioni di Economia e Finanza, (34).

Czernich, N. (2012): "Broadband Internet and Political Participation: Evidence for Germany," Kyklos, 65(1), 31-52.

Dalton, R. (2004): Democratic Challenges, Democratic Choices: The Erosion of Political Support in Advanced Industrial Democracies, Comparative Politics. Oxford University Press, UK.

DellaVigna, S., And M. GentzKow (2010): "Persuasion: Empirical Evidence," Annual Review of Economics, 2(1), 643-669.

DellaVigna, S., And E. Kaplan (2007): “The Fox News effect: Media bias and voting," The Quarterly Journal of Economics, 122(3), 1187-1234. 
Durante, R., And B. Knight (2012): "Partisan control, media bias, and viewer responses: Evidence from Berlusconi's Italy," Journal of the European Economic Association, 10(3), 451-481.

Ellman, M., And F. Germano (2009): "What do the Papers Sell? A Model of Advertising and Media Bias," Economic Journal, (119), 680-704.

ENikolopov, R., M. Petrova, AND K. SONIN (2012): "Do political blogs matter? Corruption in state-controlled companies, blog postings, and DDoS attacks," (Working Paper).

FAlck, O., R. Gold, And S. Heblich (2012): "E-lections: Voting behavior and the internet," (IZA Discussion Paper).

FARrell, H. (2012): “The Consequences of the Internet for Politics," Annual Review of Political Science, $15,35-52$.

FEddersen, T. J., AND W. PESEndorfer (1996): “The swing voter's curse,” The American economic review, pp. 408-424.

(1999): "Abstention in elections with asymmetric information and diverse preferences," American Political Science Review, pp. 381-398.

FRANKLIN, M. N. (2004): Voter turnout and the dynamics of electoral competition in established democracies since 1945. Cambridge University Press.

Gentzkow, M. (2006): “Television and voter turnout,” Quarterly Journal of Economics, 121(3), 931-972.

GentzKow, M., AND J. M. ShapIRo (2011): “Ideological segregation online and offline," Quarterly Journal of Economics, 126(4), 1799-1839.

Gentzkow, M., J. M. Shapiro, And M. Sinkinson (2011): "The Effect of Newspaper Entry and Exit on Electoral Politics," American Economic Review, 101, 2980-3018.

George, L. (2008): "The Internet and the Market for Daily Newspapers," The B.E. Journal of Economic Analysis and Policy, 8(1), 26.

Gillett, S. E., W. H. Lehr, C. A. Osorio, And M. A. Sirbu (2006): "Measuring the Economic Impact of Broadband Deployment," MIT Broadband Working Group.

Hindman, M. (2009): The myth of digital democracy. Princeton University Press.

Hirschman, A. O. (1970): Exit, voice, and loyalty: Responses to decline in firms, organizations, and states, vol. 25. Cambridge, Mass.: Harvard University Press.

Impiglia, P., F. Laurenti, L. Magnone, And R. Persico (2004): "La rete in rame di Telecom Italia: caratteristiche e potenzialità per lo sviluppo delle tecnologie xDS," Notiziario Tecnico Telecom Italia, 13(1), 74-89.

ISTAT (2013): "Noi Italia. 100 statistiche per capire il Paese in cui viviamo," .

JABER, A. (2013): "Individual Campaign Contributions and Voter Turnout: The Role of Broadband Network Availability," Working Paper, (Cornell University).

LARCinese, V., AND L. Miner (2012): “The Political Impact of the Internet on US Presidential 
Elections.," Working Paper, (LSE and New Economic School).

LASSEN, D. D. (2005): "The effect of information on voter turnout: Evidence from a natural experiment," American Journal of Political Science, 49(1), 103-118.

MatsusaKa, J. G. (1995): "Explaining voter turnout patterns: An information theory," Public Choice, 84(1-2), 91-117.

MCChesney, R. W. (2007): Communication revolution: Critical junctures and the future of media. New Press.

Miner, L. (2012): “The Unintended Consequences of Internet Diffusion: Evidence from Malaysia," Working Paper, (New Economic School).

Mosca, L., And C. VacCAri (2013): "Il Movimento e la rete," in Il Partito di Grillo, ed. by P. Corbetta, and E. Gualmini. Il Mulino.

MyatT, D. P. (2012): “A Theory of Protest Voting,” Working Paper, (Oxford University).

OECD (2001): "The Development of Broadband Access in OECD Countries," .

- (2008): "Broadband Growth and Policies in OECD Countries," .

Passarelli, G., F. Tronconi, And D. Tuorto (2013): "Dentro il Movimento: organizzazione, attivisti e programmi," in Il Partito di Grillo, ed. by P. Corbetta, and E. Gualmini. Il Mulino.

Pedrazzani, A., And L. Pinto (2013): “Gli elettori del Movimento 5 stelle.," in Il Partito di Grillo, ed. by P. Corbetta, and E. Gualmini. Il Mulino.

Pharr, S. J., R. D. Putnam, And R. J. Dalton (2000): "A quarter-century of declining confidence," Journal of democracy, 11(2), 5-25.

PiketTy, T. (2000): "Voting as communicating," The Review of Economic Studies, 67(1), 169-191.

Prat, A., And D. Strömberg (2011): “The Political Economy of Mass Media,” CEPR Discussion Paper 8246.

PRIOR, M. (2007): Post-broadcast democracy: How media choice increases inequality in political involvement and polarizes elections. Cambridge University Press.

Putnam, R. D. (2001): Bowling Alone: The Collapse and Revival of American Community. New York: Simon and Schuster.

RAZIN, R. (2003): "Signaling and election motivations in a voting model with common values and responsive candidates," Econometrica, 71(4), 1083-1119.

STRÖMBERG, D. (2004): "Radio's impact on public spending," The Quarterly Journal of Economics, 119(1), 189-221.

Sunstein, C. R. (2009): Republic.com 2.0. Princeton University Press.

Tuorto, D. (2006): Apatia o protesta?: l'astensionismo elettorale in Italia. Il mulino.

Vignati, R. (2013): "Beppe Grillo: dalla Tv ai palasport, dal blog al Movimento.," in Il Partito di Grillo, ed. by P. Corbetta, and E. Gualmini. Il Mulino. 
Figure 1: Evolution of Broadband Access and Penetration in Italian Municipalities
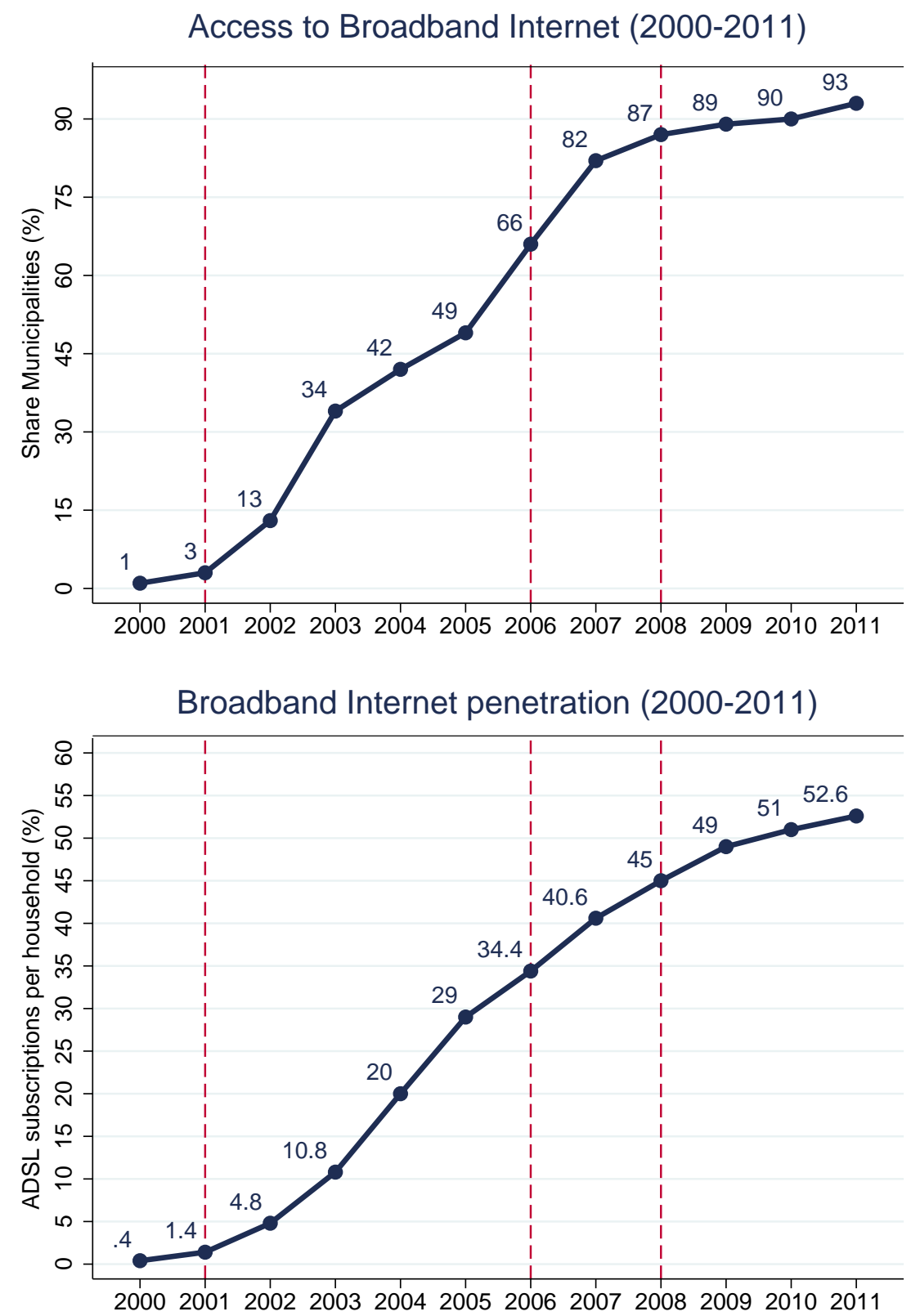

The figure reports the evolution of ADSL availability (top panel) and Internet penetration (share of households with an ADSL subscription, bottom panel), between 2000 and 2011; the dashed vertical lines indicate national elections years (2001, 2006, and 2008). Source: Between $(2006,2008)$ for ADSL access, and Between (2006, 2008) and AGCOM (2008-2012) for Internet penetration. 
Figure 2: Geographical Distribution of ADSL Access in 2005

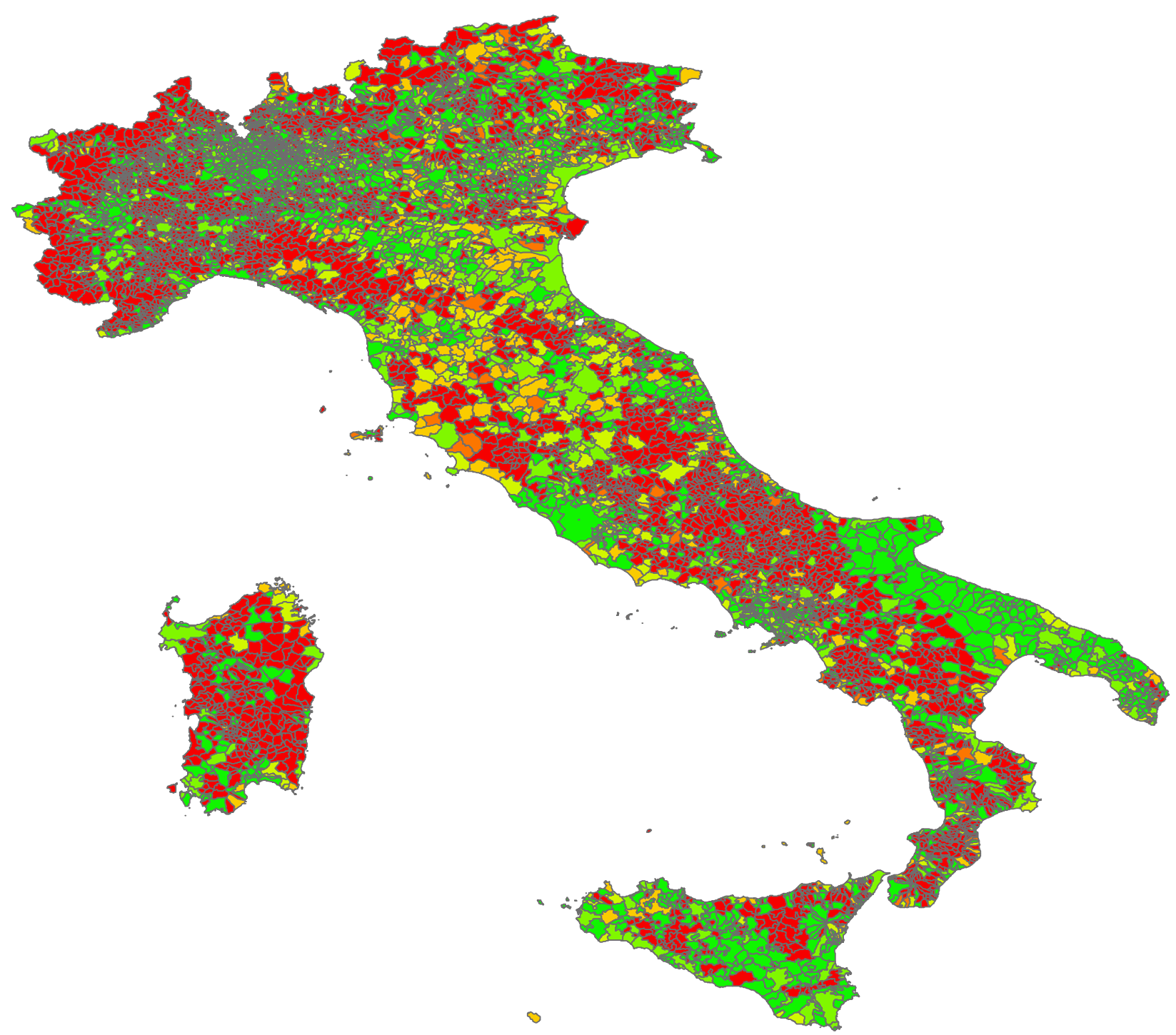

The figure illustrates the distribution of ADSL access across Italian municipalities at the end of 2005 on the 6-point scale used in our data, with darker colors indicating no or low access and lighter colors indicating high or full access. Source: Between. 
Figure 3: ADSL Coverage (2006) by Distance to Closest UGS

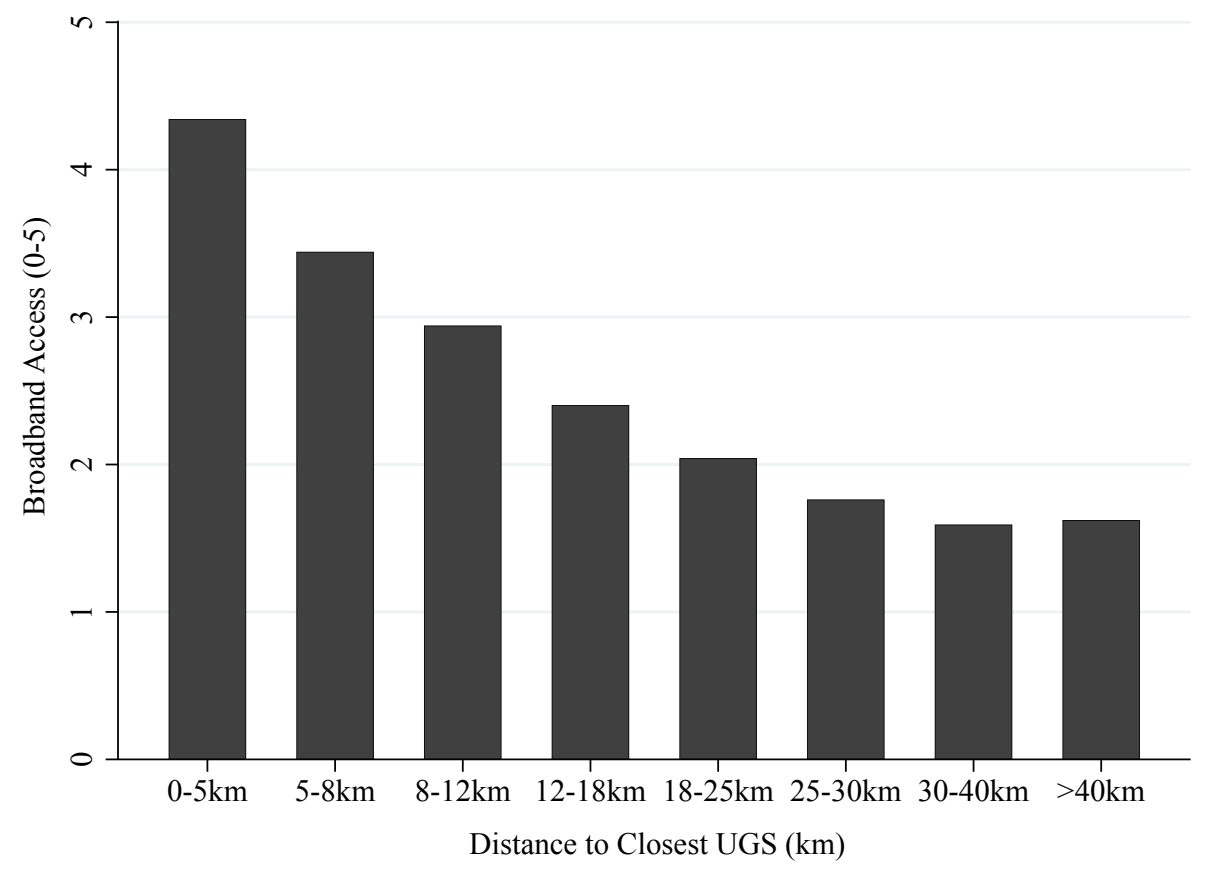

The figure reports the average ADSL access score (from 0 to 5) in 2006 for municipalities located at various distances from the closest UGS (from $0-5 \mathrm{~km}$ to $40 \mathrm{~km}$ or more). Source: Between.

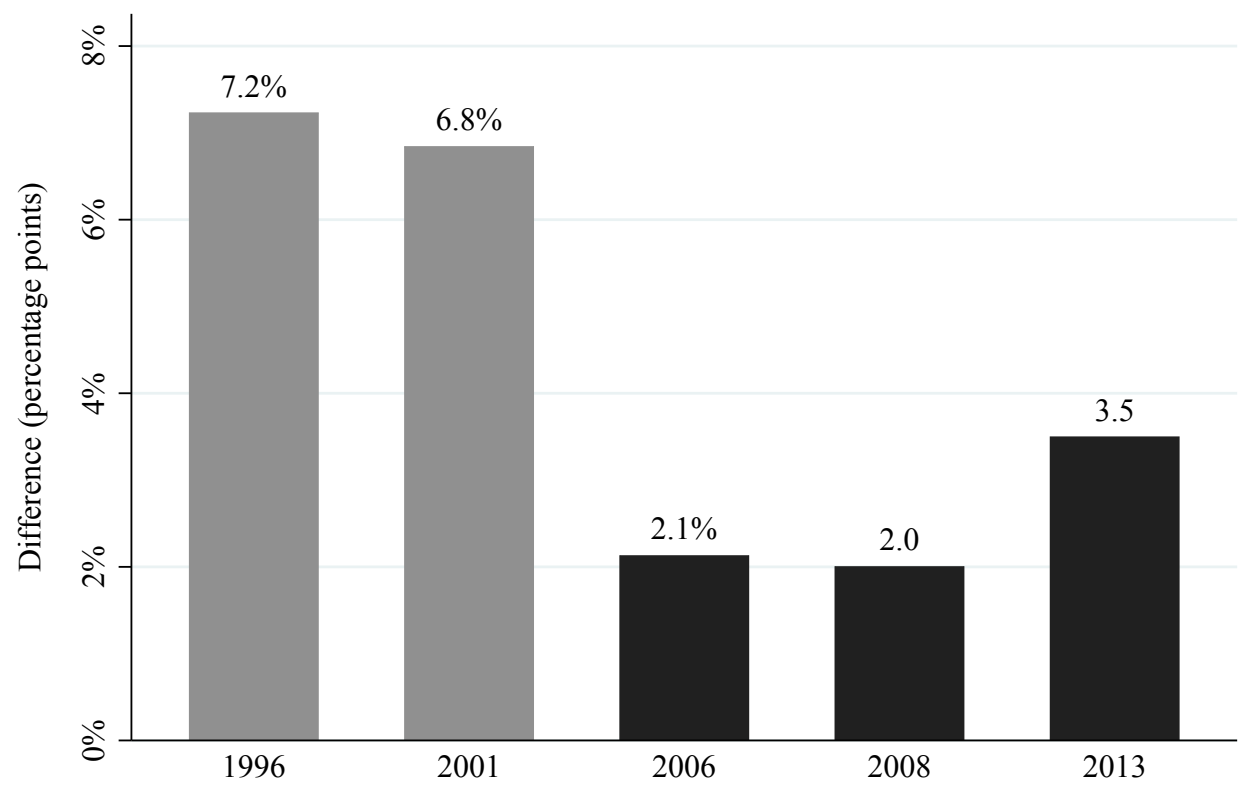

The figure reports the difference in average turnout in the national elections hold in 1996, 2001 (before the diffusion of ADSL, in light grey) and in 2006, 2008 and 2013 (after, in dark grey) between municipalities that had access to ADSL in 2005 (the first year for which data are available) and municipalities that still did not have access to ADSL in 2008. 
Figure 5: Turnout by Election Year

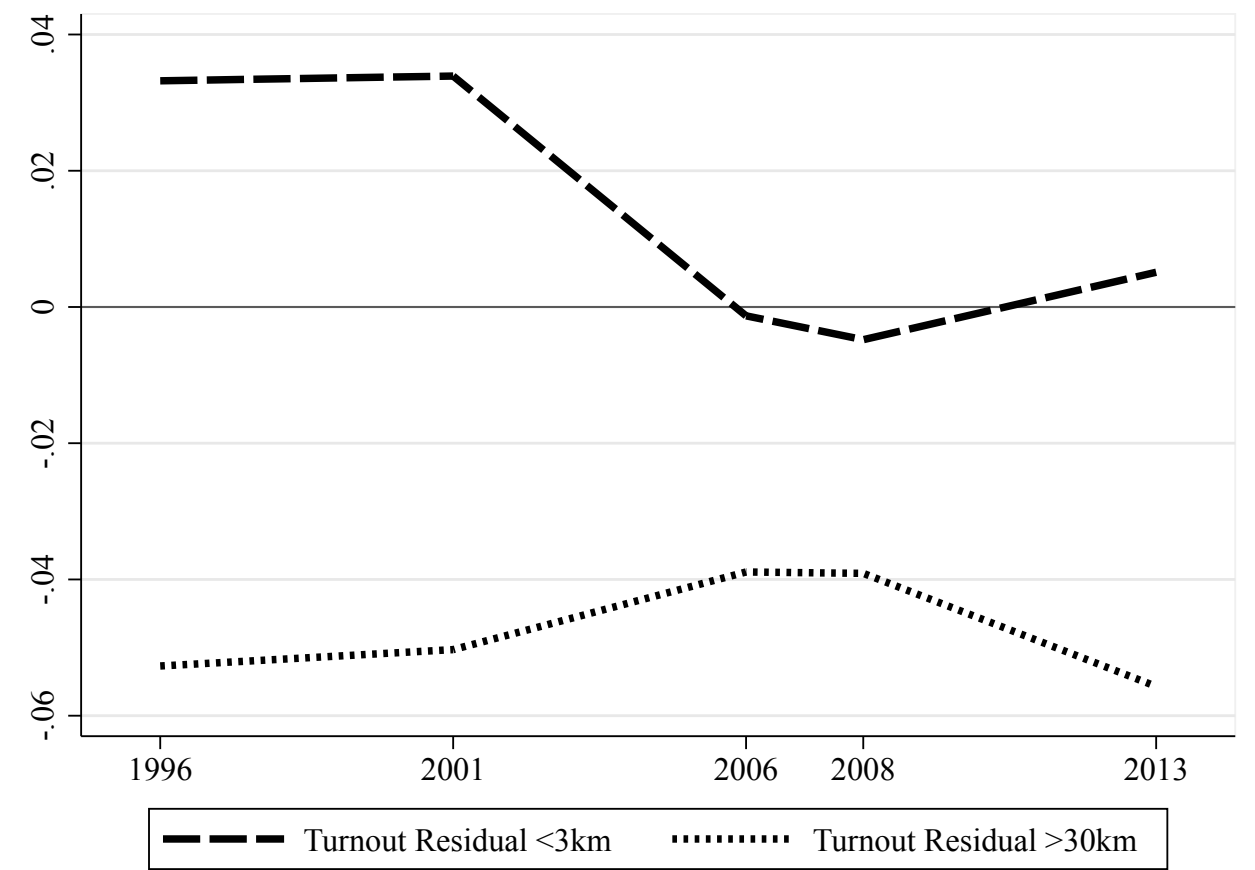

The figure reports the residual of a regression of electoral turnout in the four national elections between 1996 and 2013 on year fixed effects separately for municipalities located $3 \mathrm{~km}$ or less (top panel) and $30 \mathrm{~km}$ or more (bottom) from the closest UGS.

Figure 6: Coefficient from Reduced-Form Regression of Turnout on Distance from Closest UGS (1996-2013)

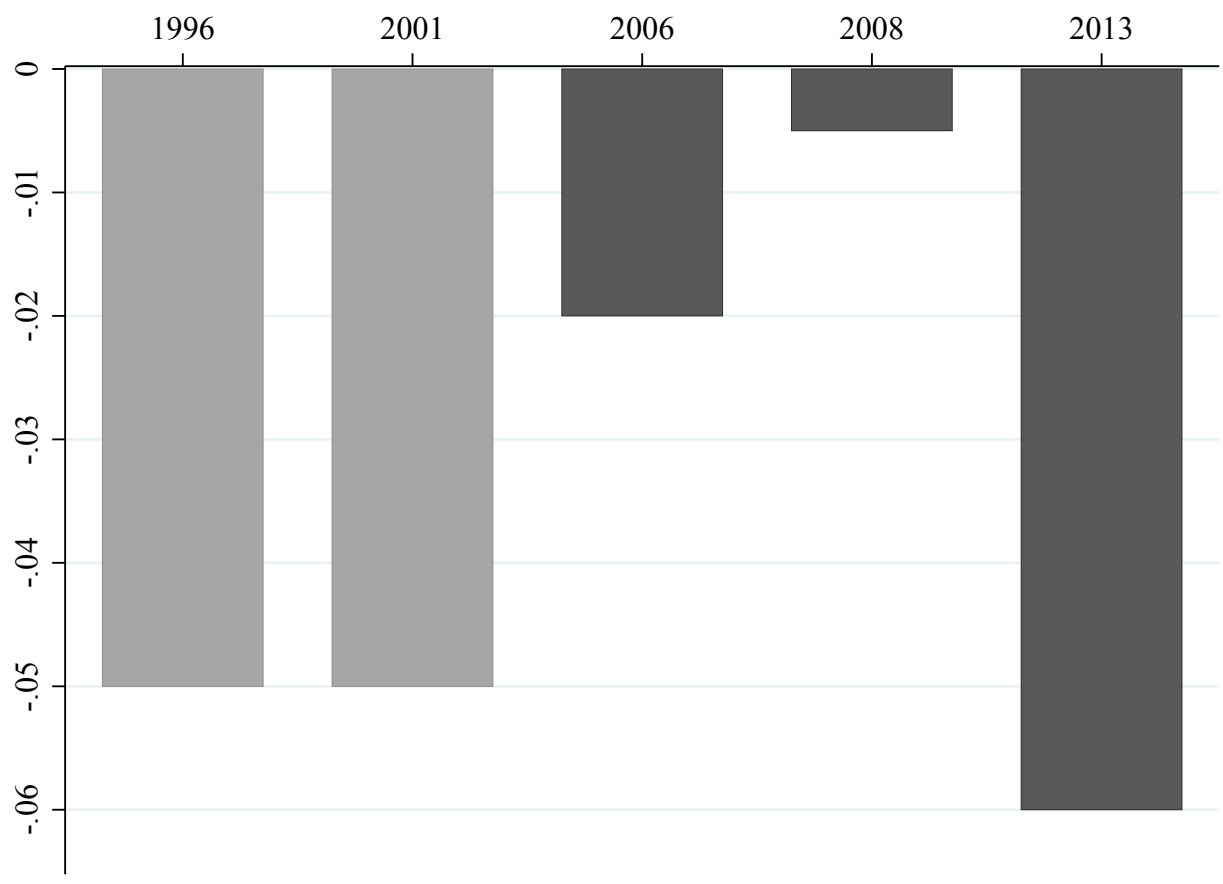

The figure reports the estimated coefficient from a regression of electoral turnout on distance from the closest UGS separately for the two pre-broadband elections (1996 and 2001, in light grey) and for the three post-broadband elections (2006, 2008 and 2013, in dark grey). All regressions include province and local labor market fixed effects as well as the entire set of controls described in our empirical section. 
Figure 7: Interest in Politics, Political Activism and Political Information by Voting Choice (2001)

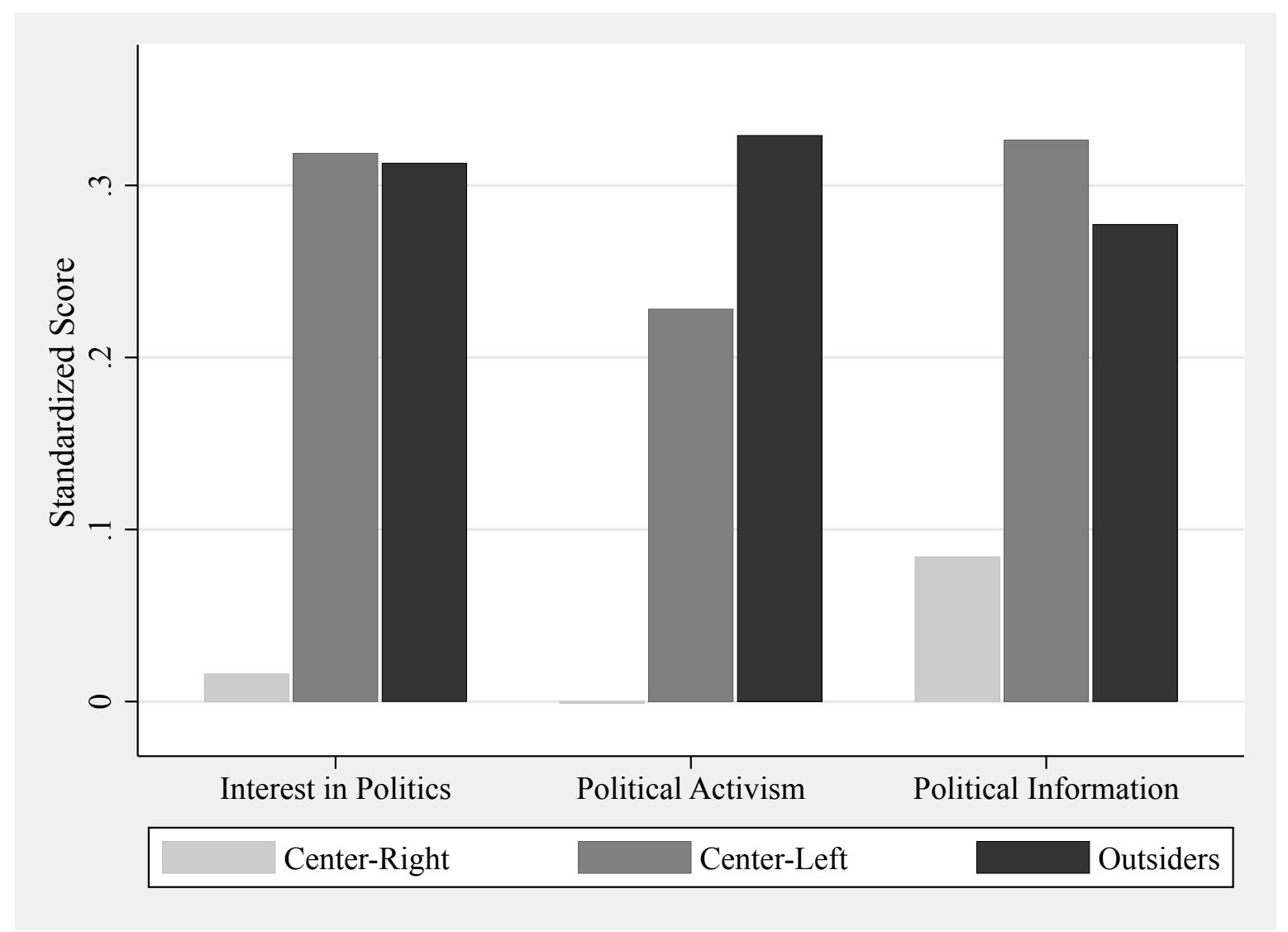

The figure reports the average standardized score in the measures "Interest in Politics", "Political Activism" and "Political Information" separately for voters of the two mainstream coalitions (Center-Right and CenterLeft), and of outsider parties. The measures are based on responses to questions included in the 2001 wave of the Italian National Election Study. The variable "Interest in Politics" is based on responses to the question "Generally speaking, are you very interested, fairly interested, a little interested or not at all interested in politics?", with the score recoded as increasing from 0 ("Not at all") to 4 ("Very much"). The variable "Political Activism" is derived from the responses to the following set of questions, by computing the first principal component: "I shall now read a list of things people sometimes do to participate in political life. Please, tell me whether you happened to make any of these things in the last 4-5 years (Yes or No): 1. Signing for law proposals or referenda; 2. Signing in favour of a candidate's or a list's presence in the ballot; 3. Sending letters or complains to public authority; 4. Writing a letter to a newspaper; 5. Participating in a political debate; 6. Participating in a demonstration; 7 . Donating money to a candidate, a party or a party's paper; 8. Spending time or work for a party; 9. Attempting to persuade somebody (including family members) to vote for a party or a candidate". Finally, the variable "Political Information" is derived from the responses to the following set of questions, again by computing the first principal component: "Now, I shall read a list of things people did during the last election campaign. For each of them, please tell me if you happened to do it or not. And if you did it, did you do it with interest or without it? 1. Listening radio programs about the elections; 2. Watching television programs about the elections; 3 . Reading articles in newspapers or magazines on the elections; 4. Participating in public speeches and meetings about the elections; 5. Reading Internet websites about the elections; 6. Looking at posters about the elections; 7.Watching TV parties' advertisements; 8. Reading flyers or propaganda letters found in my mailbox". 
Table 1: Short-run effect of Internet on Exit and Voice

Voter types High Engagement Low Engagement

High Satisfaction Voice Exit

(Entertainment)

Low Satisfaction

Exit Exit

(Non-Mainstream Politics) (Entertainment)

Table 2: Broadband and Turnout in National Lower House Elections: “Short-Run” Effects (1996-2008)

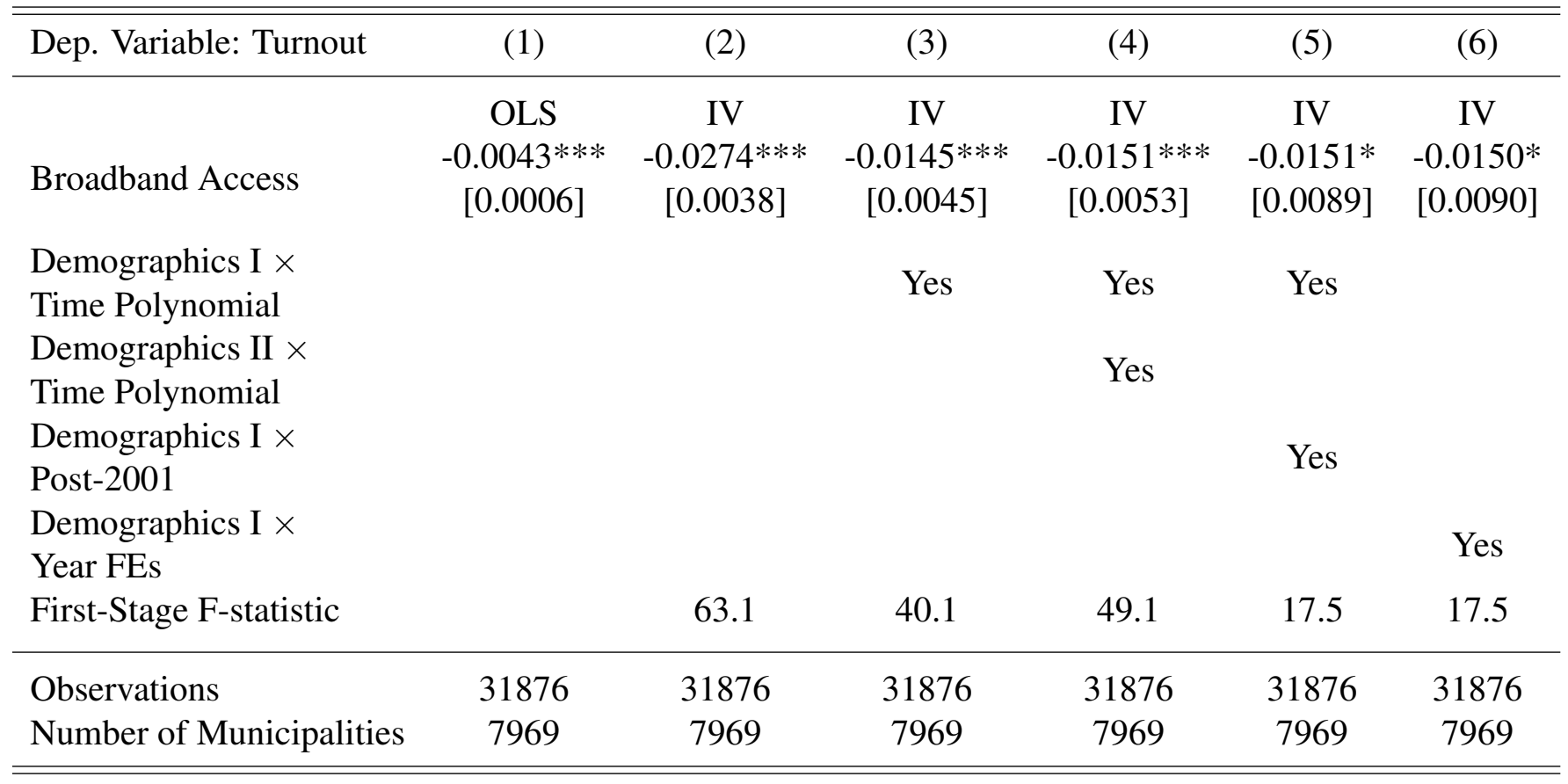

Years: 1996, 2001, 2006, 2008. All regressions include municipality and region-year fixed effects, and control for contemporaneous population. Standard errors clustered by province. Instrumental Variable: Distance from Closest UGS X Post-2001 dummy. Demographic Controls I (2001): Population, \% Population 20 to 34, \% Population over 65, Urbanization; Demographic Controls II: \% Population with Diploma Laurea, Firms per capita, Distance from Closest Provincial Capital. Time Polynomial: 4th order polynomial in time. ${ }^{*} \mathrm{p}<0.1, * * \mathrm{p}<0.05, * * * \mathrm{p}<0.01$. 


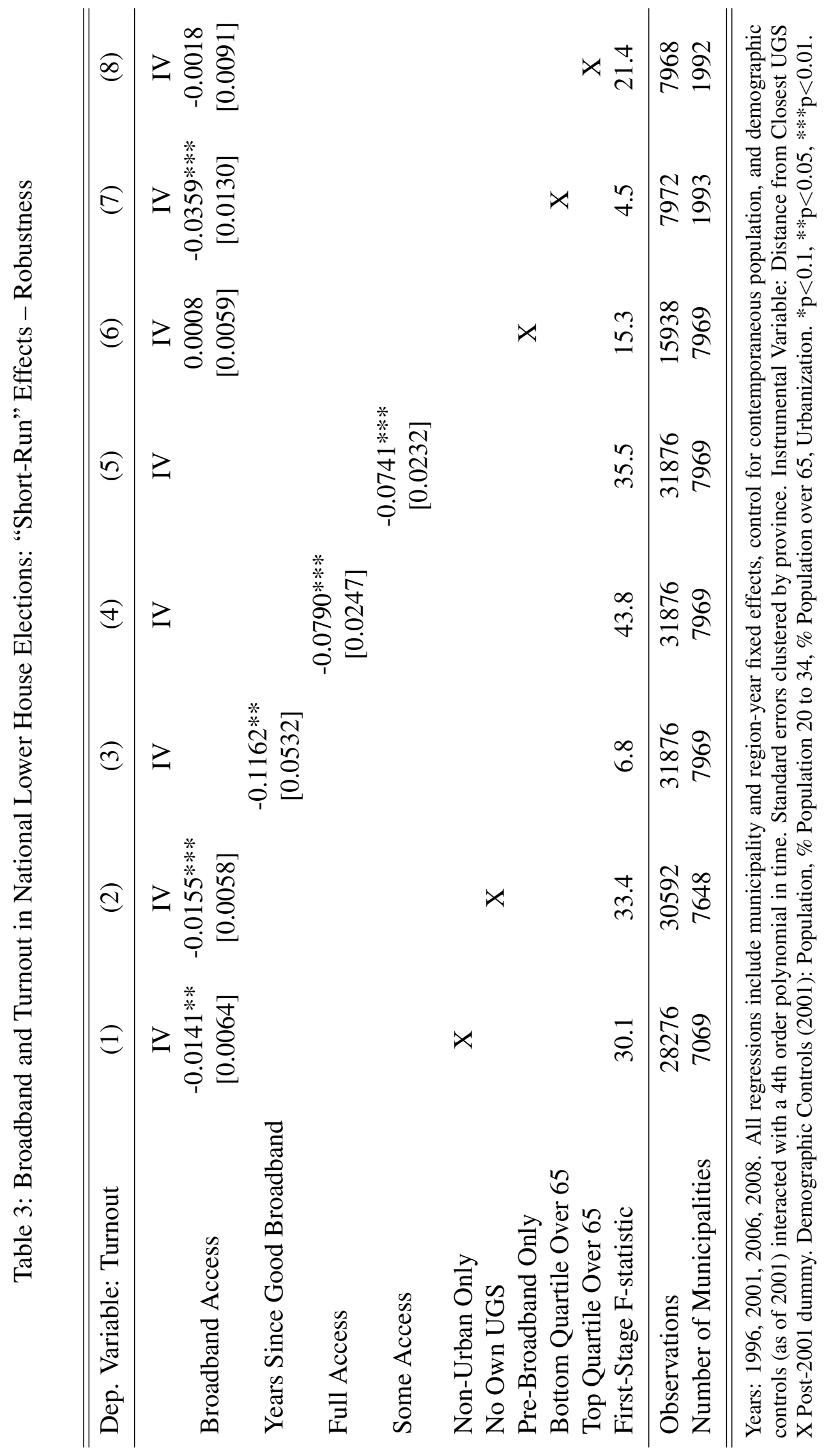


Table 4: Broadband and Turnout in National Lower House Elections: "Long-Run” Effects (2013)

\begin{tabular}{lcccccc}
\hline \hline Dep. Variable: Turnout & $(1)$ & $(2)$ & $(3)$ & $(4)$ & $(5)$ & $(6)$ \\
\hline & IV & IV & IV & IV & IV & IV \\
Broadband Access & 0.0150 & 0.0187 & & & & \\
& {$[0.0159]$} & {$[0.0167]$} & & & & \\
Years Since Good Broadband & & & 0.0086 & 0.0105 & & \\
& & & {$[0.0088]$} & {$[0.0090]$} & & 0.0640 \\
Full Access & & & & & {$[0.0673]$} & \\
& & & & & & 0.0869 \\
Some Access & & & & & & \\
Non-Urban Only & & & & & & \\
First-Stage F-statistic & 13.0 & 13.6 & 13.5 & 15.3 & 12.8 & 11.5 \\
\hline Observations & 23907 & 21207 & 23907 & 21207 & 23907 & 23907 \\
Number of Municipalities & 7969 & 7069 & 7969 & 7069 & 7969 & 7969 \\
\hline \hline
\end{tabular}

Years: 1996, 2001, 2013. All regressions include municipality and region-year fixed effects, control for contemporaneous population, and demographic controls (as of 2001) interacted with a 4th order polynomial in time. Standard errors clustered by province. Instrumental Variable: Distance from Closest UGS X Post-2001 dummy. Demographic Controls (2001): Population, \% Population 20 to 34, \% Population over 65, Urbanization. $* \mathrm{p}<0.1, * * \mathrm{p}<0.05, * * * \mathrm{p}<0.01$. 
Table 5: Broadband and Turnout in National Lower House Elections: Full Sample (1996-2013)

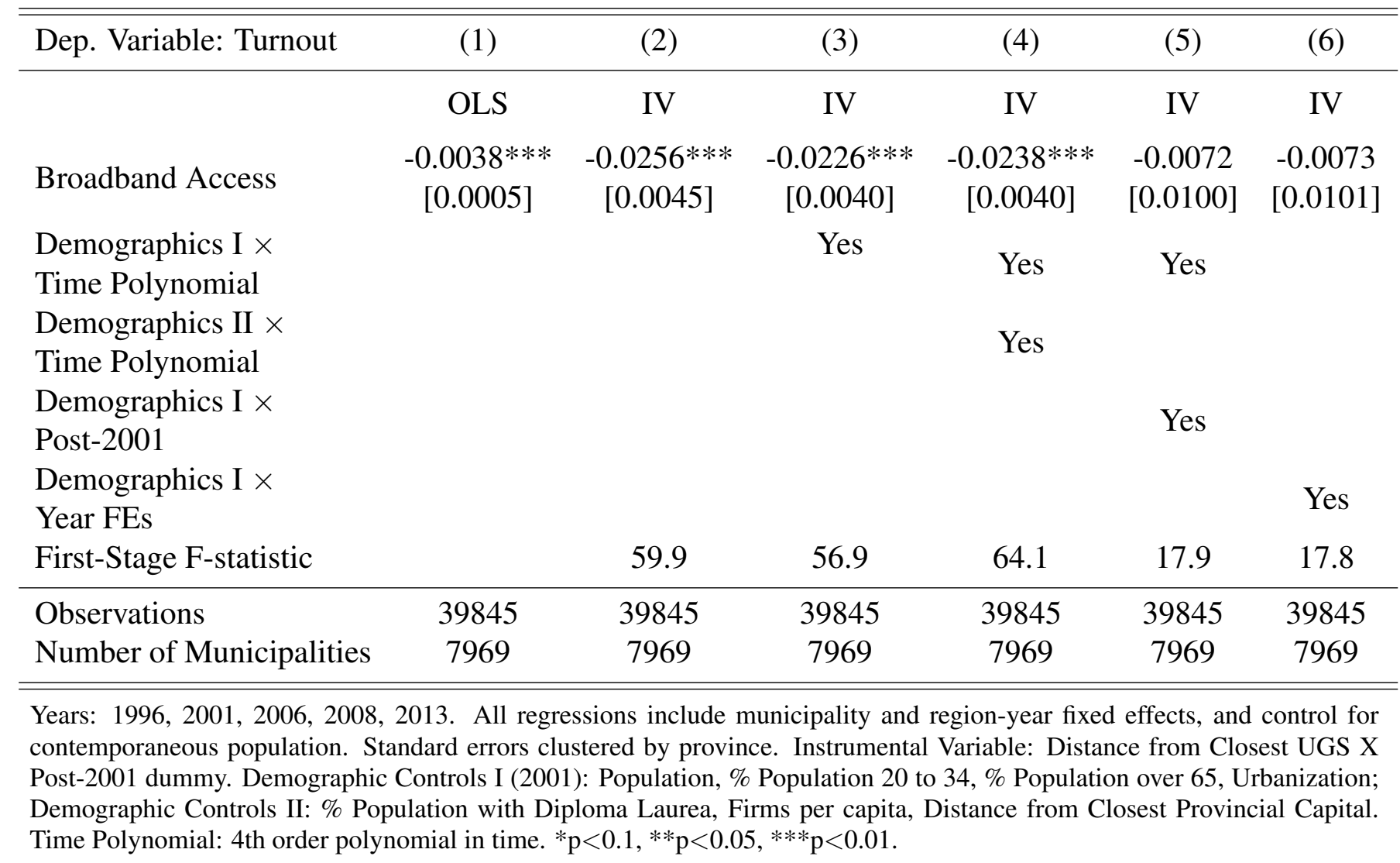

Table 6: Broadband and Coalition Performance: 2001 and 2008 (IV Results)

\begin{tabular}{lccc}
\hline \hline & $(1)$ & $(2)$ & $(3)$ \\
\hline Dependent Variable: & Center-Right & Center-Left & Outsiders \\
Vote Share & 0.0086 & $0.0115^{*}$ & $-0.0287 * * *$ \\
Mean Vote Share 2001) & {$[0.0091]$} & {$[0.0062]$} & {$[0.0119]$} \\
Votes per eligible voters & 0.516 & 0.320 & 0.150 \\
(Mean Votes per eligible voter 2001) & -0.0057 & 0.0017 & $-0.0237 * * *$ \\
\hline Observations & $0.0053]$ & {$[0.0051]$} & {$[0.0089]$} \\
Number of Municipalities & 15938 & 0.232 & 0.107 \\
\hline \hline
\end{tabular}

Years: 2001 and 2008. Reported coefficients are for Broadband Access. All regressions include municipality and region-year fixed effects, control for contemporaneous population, and demographic controls (as of 2001) interacted with a 4th order polynomial in time. Standard errors clustered by province. Instrumental Variable: Distance from Closest UGS X Post-2001 dummy. Demographic Controls (2001): Population, \% Population 20 to 34, \% Population over 65, Urbanization. *p $<0.1$, $* * \mathrm{p}<0.05, * * * \mathrm{p}<0.01$. 
Table 7: Broadband and Coalition Performance in National Elections: 2001 and 2013 (IV Results)

\begin{tabular}{lccccc}
\hline \hline Votes per eligible voter & $(1)$ & $(2)$ & $(3)$ & $(4)$ & $(5)$ \\
& M5S & Mainstream & Outsiders & Fare & Monti \\
\hline Years Since Good Broadband & $0.0257^{* * *}$ & -0.0138 & $-0.0145^{* * *}$ & $0.0021^{* * * *}$ & $0.0082^{* *}$ \\
Mean (2013) & {$[0.0072]$} & {$[0.0086]$} & {$[0.0054]$} & {$[0.0006]$} & {$[0.0037]$} \\
\hline Observations & 0.170 & 0.430 & 0.035 & 0.007 & 0.060 \\
Municipalities & 15938 & 15938 & 15938 & 15938 & 15938 \\
\hline \hline
\end{tabular}

Years: 2001 and 2013. Reported coefficients are for Broadband Access. All regressions include municipality and region-year fixed effects, control for contemporaneous population, and demographic controls (as of 2001) interacted with a 4 th order polynomial in time. Standard errors clustered by province. Instrumental Variable: Distance from Closest UGS X Post-2001 dummy. Demographic Controls (2001): Population, \% Population 20 to $34, \%$ Population over 65, Urbanization. $* \mathrm{p}<0.1, * * \mathrm{p}<0.05, * * \mathrm{p}<0.01$

Table 8: Broadband and Formation of Beppe Grillo/M5S Meetup.com Groups (IV Results)

\begin{tabular}{lcc}
\hline \hline & $(1)$ & $(2)$ \\
Dependent Variable: & Log Days since Formation & Members per 1000 \\
\hline Broadband Access & $1.2838^{* * *}$ & $0.1253^{* * * *}$ \\
& {$[0.4647]$} & {$[0.0445]$} \\
Years & 2012 & $2001,2005-2011$ \\
Demographic Controls (2001) & Yes & \\
Province and SLL FEs & Yes & Yes \\
Demographics $\times$ Time Polynomial & & Yes \\
Municipality and Region-Year FEs & & 78.7 \\
First-Stage F-statistic & 12.4 & 64680 \\
\hline Observations & 8066 & 8085 \\
Number of Municipalities & & \\
\hline \hline
\end{tabular}

Log Days since Formation: Log (1 + Days since Formation of First Group). Members per 1000: Number of Affiliates per 1000 Inhabitants. Instrumental Variable: Distance from Closest UGS (Column (1)), Distance from Closest UGS X Post-2001 (Column (2)). Demographic controls (2001): Population, \% Population 20 to 34, \% Population over 65, Urbanization, \% of Population with Diploma Laurea, Firms per capita, Distance from Closest Provincial Capital. Standard errors are clustered at the province level. $* \mathrm{p}<0.1, * * \mathrm{p}<0.05, * * * \mathrm{p}<0.01$. 
Table 9: Broadband, Turnout, and M5S Results in Municipal Elections

\begin{tabular}{|c|c|c|c|c|}
\hline & (1) & (2) & (3) & (4) \\
\hline Dependent Variable: & $\begin{array}{c}\text { M5S } \\
\text { on Ballot }\end{array}$ & $\begin{array}{l}\text { M5S } \\
\text { on Ballot }\end{array}$ & $\begin{array}{c}\text { M5S Votes } \\
\text { per eligible voters }\end{array}$ & $\begin{array}{c}\text { M5S Votes } \\
\text { per eligible voters }\end{array}$ \\
\hline Broadband Access & $\begin{array}{c}0.0749 * * * * \\
{[0.0237]}\end{array}$ & & $\begin{array}{l}0.0018^{* *} \\
{[0.0008]}\end{array}$ & \\
\hline Years Since Good Broadband & & $\begin{array}{l}0.1198 * * \\
{[0.0484]}\end{array}$ & & $\begin{array}{l}0.0030 * * \\
{[0.0014]}\end{array}$ \\
\hline Observations & 7299 & 7299 & 7299 & 7299 \\
\hline
\end{tabular}

Years: 2008-2011 (Columns (1)-(2)), 2008-2012 (Columns (3)-(4)). IV Regressions. All regressions include year, provincce, and SLL fixed effects. Standard errors are clustered at the province level. Instrumental Variable: Distance from Closest UGS. Demographic controls (2001) Population, \% Population 20 to 34, $\%$ Population over 65, Urbanization, \% Population with Diploma Laurea, Firms per capita, Distance from Closest Provincial Capital. ${ }^{*} \mathrm{p}<0.1,{ }^{*} \mathrm{p}<0.05, * * \mathrm{p}<0.01$

Table 10: Broadband and Turnout in National Referenda $(2009,2011)$

\begin{tabular}{lcccc}
\hline \hline Dependent Variable: Turnout & $(1)$ & $(2)$ & $(3)$ & (4) \\
\hline & \multicolumn{2}{c}{2009} & \multicolumn{2}{c}{2011} \\
& OLS & IV & OLS & IV \\
Broadband Access & 0.0006 & $0.0210^{*}$ & $0.0016^{* * *}$ & $0.0189^{*}$ \\
& {$[0.0005]$} & {$[0.0123]$} & {$[0.0005]$} & {$[0.0098]$} \\
First-Stage F-statistic & & 19.4 & & 37.2 \\
Observations & 8085 & 8085 & 8085 & 8085 \\
\hline \hline
\end{tabular}

Years: 2009 and 2011. All regressions include province and SLL fixed effects, standard errors clustered at province level. Turnout $=$ average turnout across four referendum questions. Instrumental Variable: Distance from Closest UGS. Demographic controls (2001): Population, \% Population 20 to 34, \% Population over 65, Urbanization, \% Population with Diploma Laurea, Firms per capita, Distance from Closest Provincial Capital. ${ }^{*} \mathrm{p}<0.1,{ }^{* *} \mathrm{p}<0.05,{ }^{* * *} \mathrm{p}<0.01$. 
Appendix A: Additional Tables and Figures (ONLINE ONLY) 


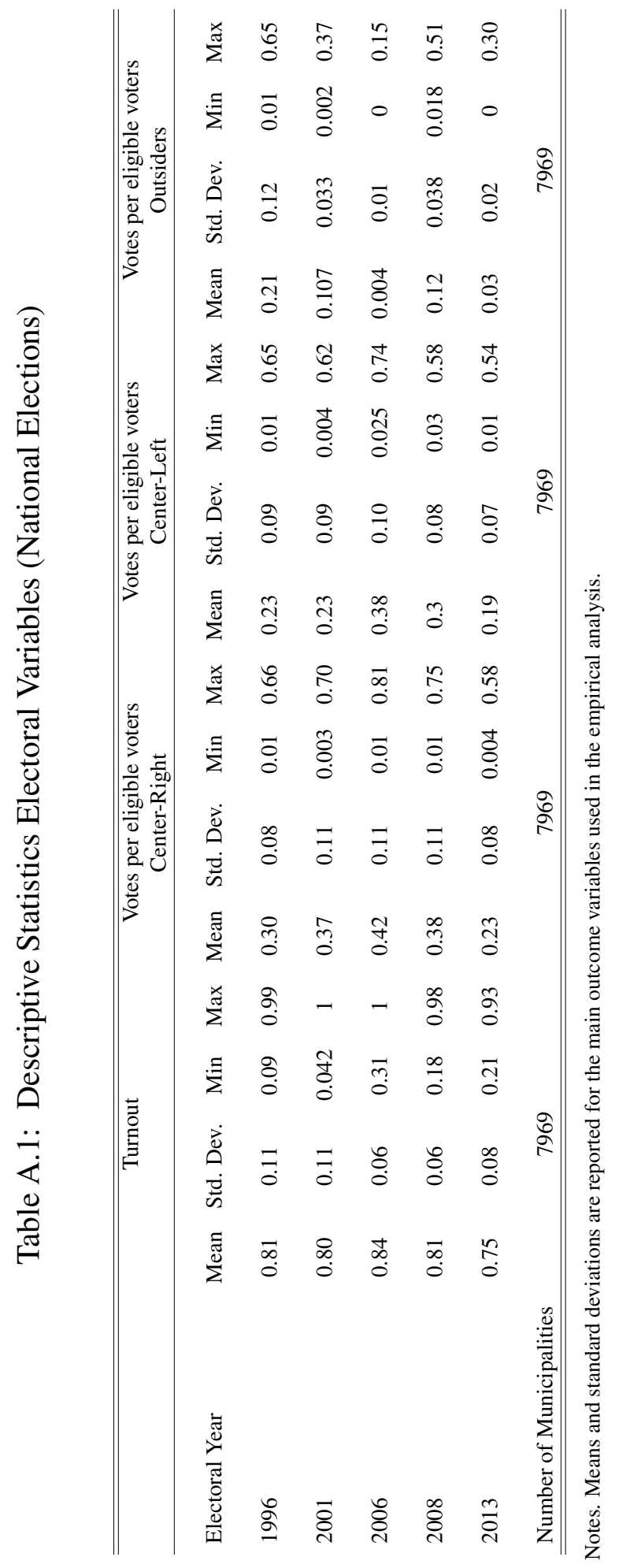




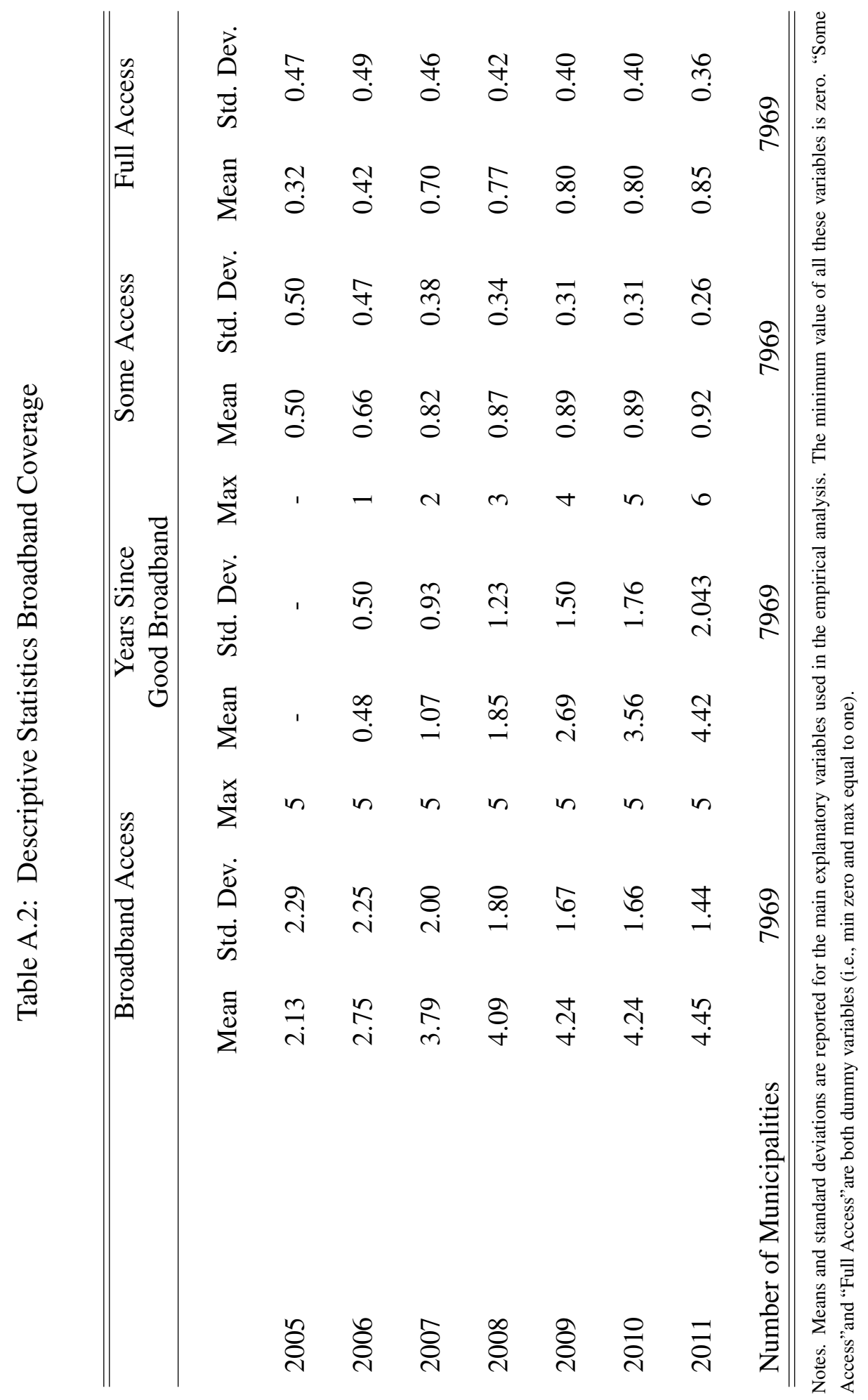


Table A.3: Descriptive Statistics - Time-invariant variables

\begin{tabular}{|c|c|c|c|c|}
\hline & Mean & S.d. & Min & Max \\
\hline \multicolumn{5}{|l|}{ Demographics I } \\
\hline Share of population $20-34$ & 0.20 & 0.03 & 0.05 & 0.32 \\
\hline Share of population over 65 & 0.21 & 0.06 & 0.06 & 0.64 \\
\hline Urbanization & 1.61 & 0.68 & 1 & 3 \\
\hline \multicolumn{5}{|l|}{ Demographics II } \\
\hline Share of graduates & 0.26 & 0.061 & 0.051 & 0.71 \\
\hline Firms per capita & 924 & 1981 & 0.04 & 76918 \\
\hline Distance to closest province capital & 23.48 & 13.32 & 0 & 209.80 \\
\hline \multicolumn{5}{|l|}{$\underline{\text { Instrument }}$} \\
\hline Distance to the closest UGS & 14.10 & 8.93 & 0 & 212.02 \\
\hline
\end{tabular}


Table A.4: Broadband, Turnout, and Demographic Characteristics: Pairwise Correlations

\begin{tabular}{lcc}
\hline \hline Broadband Access & $(1)$ & $(2)$ \\
\hline & 2006 & 2008 \\
& & \\
Turnout & 0.018 & 0.055 \\
Population (1000's) & 0.114 & 0.060 \\
\% Population 20 to 34 & 0.262 & 0.152 \\
\% Population over 65 & -0.333 & -0.223 \\
Urbanization & 0.415 & 0.232 \\
\% Population with Diploma Laurea & 0.320 & 0.197 \\
Firms per capita & -0.224 & -0.130 \\
Distance Provincial Capital & -0.156 & -0.106 \\
& & \\
\hline Observations & 7969 & 7969 \\
\hline \hline
\end{tabular}

Pairwise correlations with Broadband Access. p-values are 0.000 for all variables. 
Table A.5: Broadband, Turnout, and Demographic Characteristics: OLS Regressions

\begin{tabular}{|c|c|c|c|}
\hline Dep. Variable: Broadband Access & (1) & (2) & (3) \\
\hline Turnout & $\begin{array}{c}0.0018 * * * \\
{[0.0004]}\end{array}$ & $\begin{array}{c}0.0002 \\
{[0.0003]}\end{array}$ & $\begin{array}{c}-0.00006 \\
{[0.00029]}\end{array}$ \\
\hline Population (1000's) & & $\begin{array}{c}-0.00006^{* * *} \\
{[0.00003]}\end{array}$ & $\begin{array}{c}-0.00008^{* * *} \\
{[0.00003]}\end{array}$ \\
\hline$\%$ Population 20 to 34 & & $\begin{array}{c}-0.1034 * * \\
{[0.0426]}\end{array}$ & $\begin{array}{c}-0.0835^{* *} \\
{[0.0420]}\end{array}$ \\
\hline$\%$ Population over 65 & & $\begin{array}{c}-0.2766 * * * * \\
{[0.0229]}\end{array}$ & $\begin{array}{c}-0.2611 * * * * \\
{[0.0224]}\end{array}$ \\
\hline Urbanization & & $\begin{array}{c}0.0029 \\
{[0.0019]}\end{array}$ & $\begin{array}{l}-0.0008 \\
{[0.0017]}\end{array}$ \\
\hline \% Population with Diploma Laurea & & & $\begin{array}{c}0.0732 * * * \\
{[0.0171]}\end{array}$ \\
\hline Firms per capita & & & $\begin{array}{c}0.000002 * * * \\
{[0.0000003]}\end{array}$ \\
\hline Distance Provincial Capital & & {$[0.0001]$} & $-0.0003 * * *$ \\
\hline $\begin{array}{l}\text { Observations } \\
\text { R-squared }\end{array}$ & $\begin{array}{l}7969 \\
0.542\end{array}$ & $\begin{array}{l}7969 \\
0.584\end{array}$ & $\begin{array}{l}7969 \\
0.591\end{array}$ \\
\hline
\end{tabular}

OLS regressions. Data for broadband access and turnout refer to electoral year 2008; all other variables refer to census year 2001. All regressions include province fixed effects. Standard errors clustered at the province level. $* \mathrm{p}<0.1, * * \mathrm{p}<0.05, * * * \mathrm{p}<0.01$ 


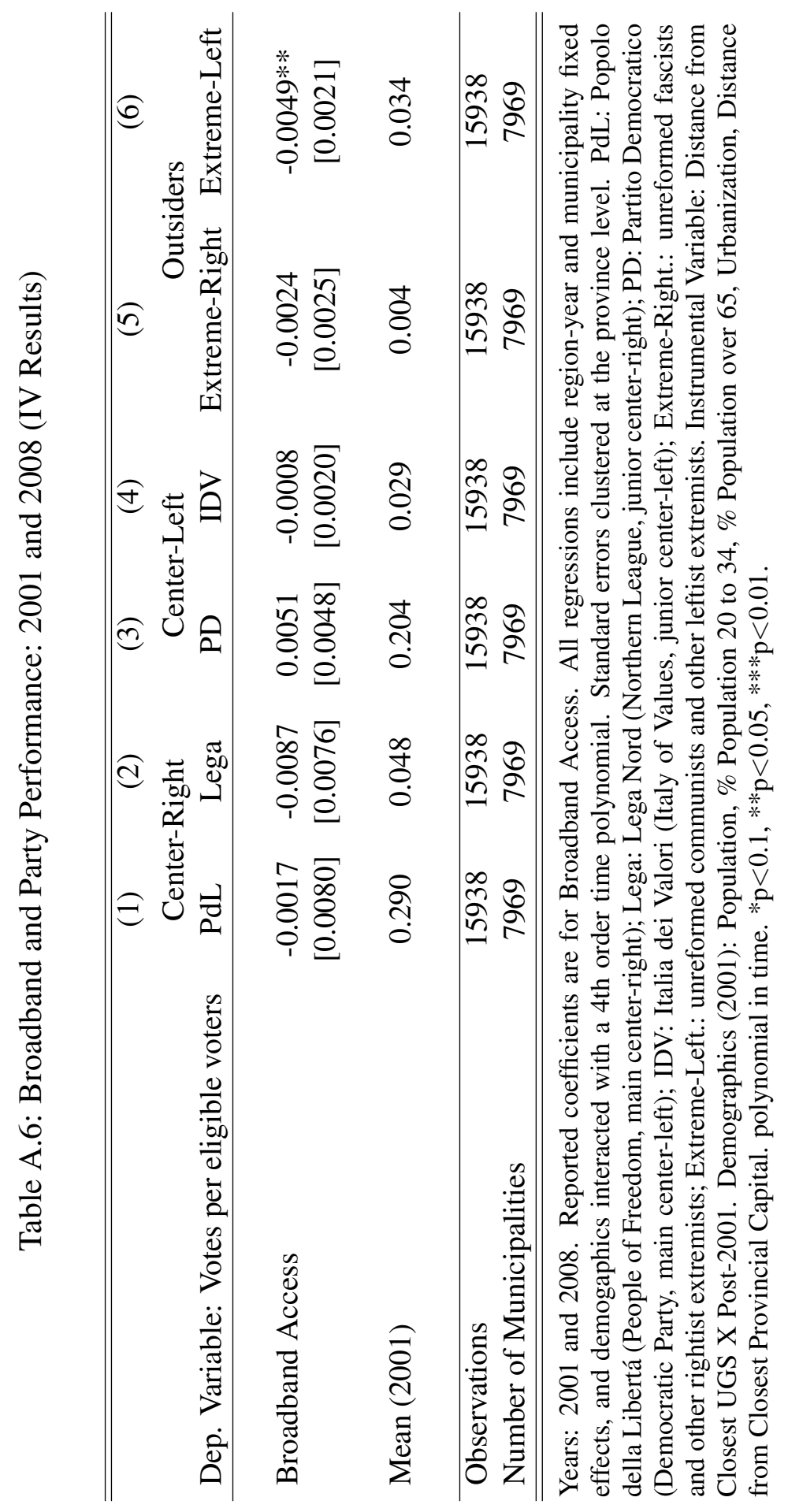




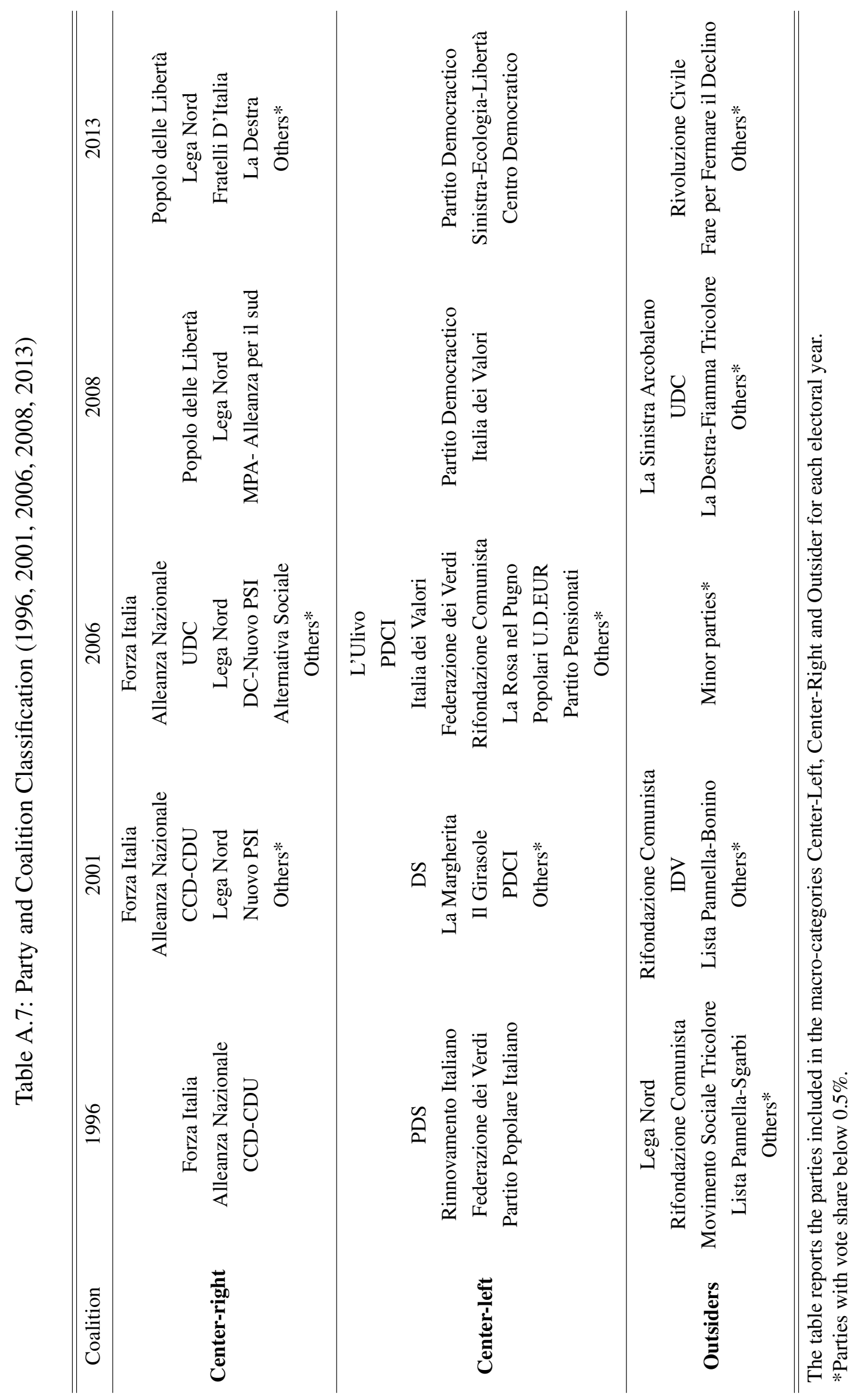




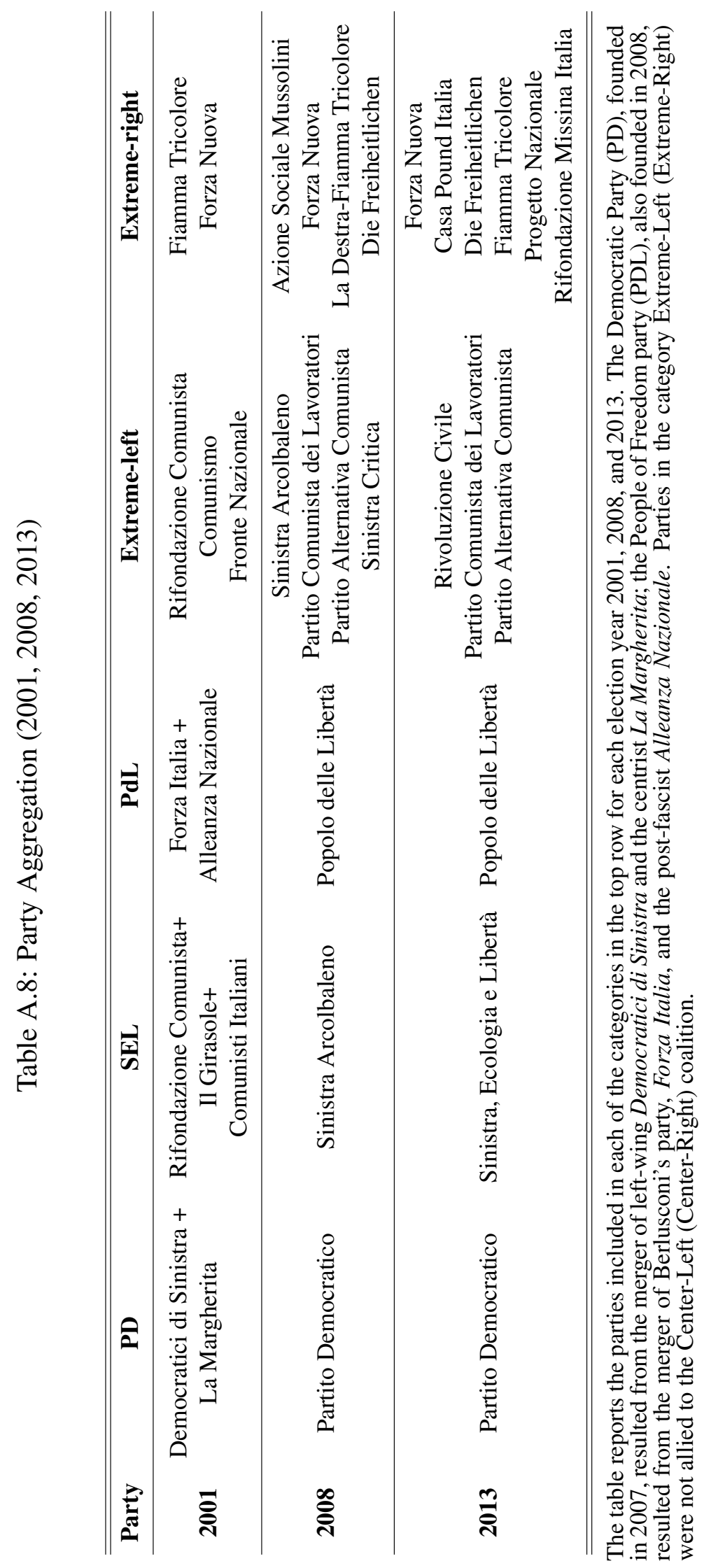


Figure A.1: Log Population by Election Year
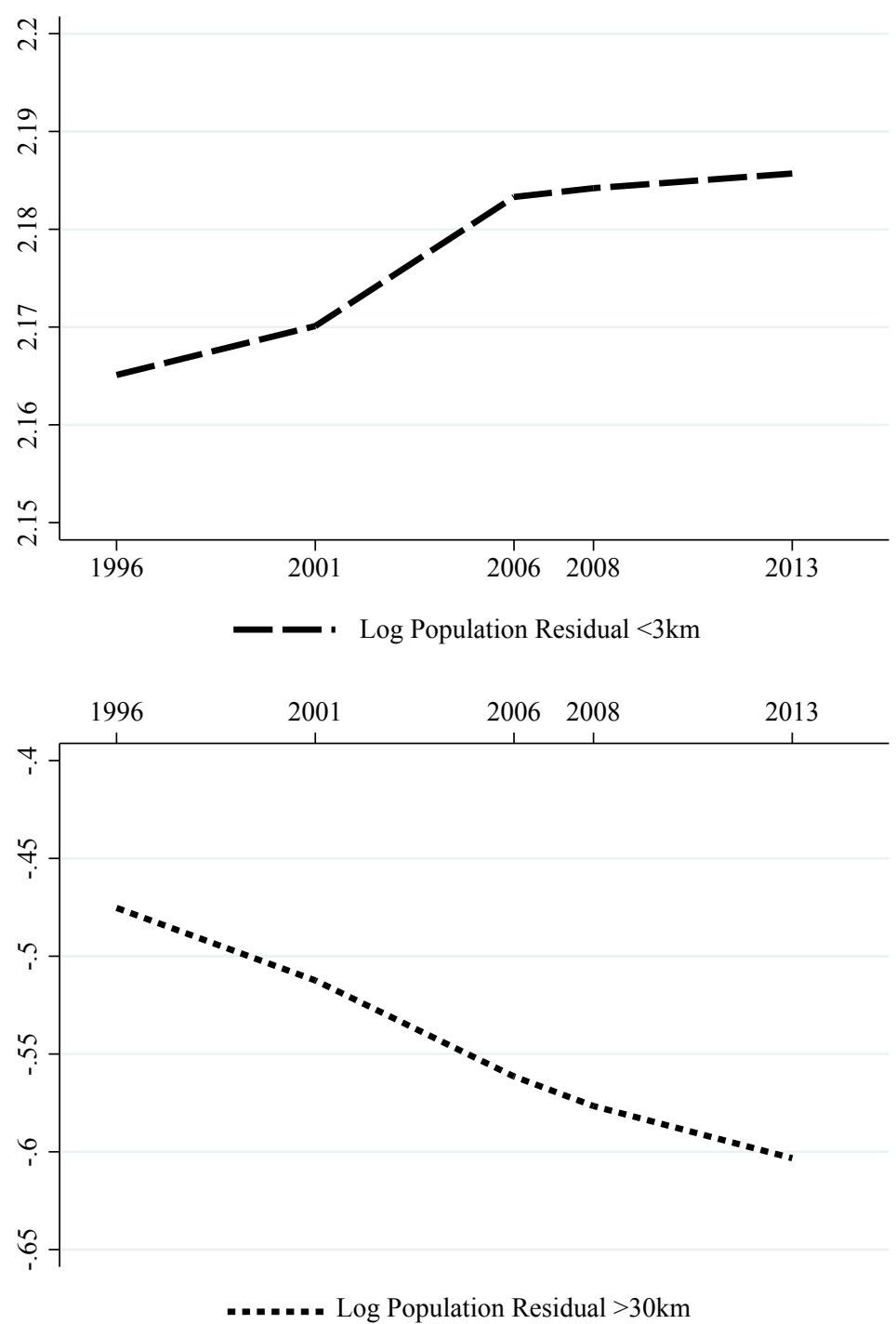

The figure reports the residual of a regression of population between 1996 and 2013 on year fixed effects separately for municipalities located $3 \mathrm{~km}$ or less (top panel) and $30 \mathrm{~km}$ or more (bottom) from the closest UGS. 


\section{APPENDIX B: TECHNICAL BACKGROUND INFORMATION ON ITALY'S BROADBAND INFRASTRUCTURE (ONLINE ONLY)}

The average length of the Italian primary distribution network, running from the "Main Distribution Frames" (MDFs) in the local telecommunication exchange (i.e., the "Central Office", $\mathrm{CO}$ ) to the street cabinets (SDFs) is $1.3 \mathrm{~km}$. The average length of the secondary distribution network, running from the street cabinets (SDFs) to the buildings, is $0.47 \mathrm{~km} .{ }^{37}$ Indeed, the length of "local loops" does not seem to be a crucial parameter determining the absence of ADSL access by Italian municipalities even in 2011. Specifically, our data shows that $3 / 4$ of municipalities that did not yet have access to ADSL in 2011 are less than 4 kilometers away from the closest CO.

In order to provide a comprehensive picture of the Italian broadband network, it is also important to point out that in addition to deploying optical fiber cables between the $\mathrm{CO}$ serving the municipality and the closest UGS, telecommunication operators had to meet another technical requirement. Specifically, in order to be able to offer ADSL services to the municipality: it also needs to install a DSLAM (Digital Subscriber Line Multiplexer) within the Central Office. However, the installation cost of the DSLAM is remarkably lower with respect to the cost of connecting the CO to the UGS using optical fiber (Between, 2006; AGCOM, 2008-2012). ${ }^{38}$ Indeed, (AGCOM, 2011) distinguish between areas of "medium-run" and "short-run" digital divide. Municipalities served by a CO whose connection to the UGS is still implemented via copper wires (i.e., not connected with optical fiber) belong to the first category. Municipalities served by a central office connected with optical fiber to the UGS but still lacking a DSLAM, belong to the second category.

For what concerns mobile broadband, the data available at the regional and provincial level show that the pattern of its coverage resembles the one of fixed broadband. That is, the regions/provinces characterized by a lower degree of ADSL availability are also the ones with the lower coverage of mobile broadband (Between 2008). Similarly, in terms of connection speed, the digital divide on the mobile connection side follows the very same pattern as the one concerning fixed broadband. For example, the download speed in smaller municipalities (i.e., below 2000 inhabitants) is around half with respect to that of metropolitan areas (Between, 2010). Moreover, a large share of mobile

${ }^{37}$ According to other estimates by Telecom Italia the actual average distances are even lower, $1.1 \mathrm{~km}$ and $0.4 \mathrm{~km}$ for the primary and secondary distribution network, respectively. In Metropolitan areas the average length of the primary distribution network is $0.9 \mathrm{~km}$. Moreover during the 1988-1992 the telecommunication incumbent operator, Telecom Italia, invested significant resources in renovating and improving its copper distribution network (Impiglia, Laurenti, Magnone, and Persico, 2004).

${ }^{38}$ In 2008, the cost of installing optical fiber cables was estimated to be around 4,000 Euros per kilometer in small cities and 1,0000 Euros per kilometer in larger ones (i.e., requiring larger cables) in Italy. In addition to the fiber cable costs per se, the cost of digging the trenches and the costs of municipal licenses represent other relevant costs necessary to install optical fiber cables (Ciapanna and Sabbatini (2008)). The cost of installing a DSLAM in a central office varies according to the number of lines served. However, the overall cost of installing a DSLAM in an CO is in the range of few thousands euros (AGCOM 2011). 
connections are based on "pay-as-you-go" type of contracts (around 76\%) which usually have a cap in terms of either the maximum amount of downloadable data or in terms of time that could be spent surfing the web (AGCOM, 2012). Indeed, while the bandwidth available to the end user in the case of fixed broadband corresponds to her "dedicated" one through her own copper wire, in the case of mobile connection the bandwidth of the end user has to be shared with everyone else using the same mobile cell. Thus, while the users of fixed line broadband experience a good average bandwidth speed, this is not the case for the ones using mobile connections. Hence, the differences between the type of contracts typically observed in the fixed and mobile broadband markets, "flat" and "pay-asyou-go", respectively, reflect these differences in the bandwidth availability (Between, 2008). Finally and most importantly, most of the active mobile connections are used by customers who already have a broadband service on the fixed line, e.g., when traveling (Between, 2008). In sum, in the Italian context, mobile broadband internet connections do not seem to constitute and/or used as a valid substitute for the unavailability of ADSL in a municipality. Indeed the Italian government has recently planned to invest 900 million euros in (mainly fixed-line) infrastructures to close this digital divide (Agenda Digitale Italiana, 2013). 
Figure B.1: Length of Local Loops in Select Countries

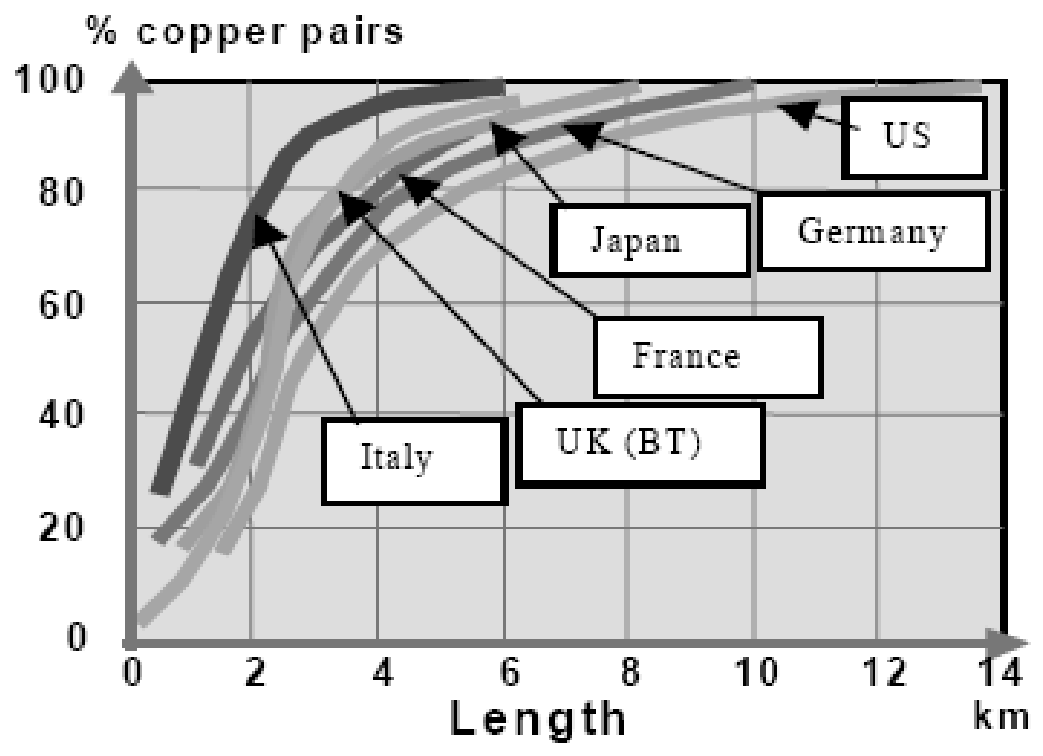

The figure illustrates the distribution of the length of "local loops" in various countries (source: OECD, 2001).

Figure B.2: Italy's Broadband Infrastructure

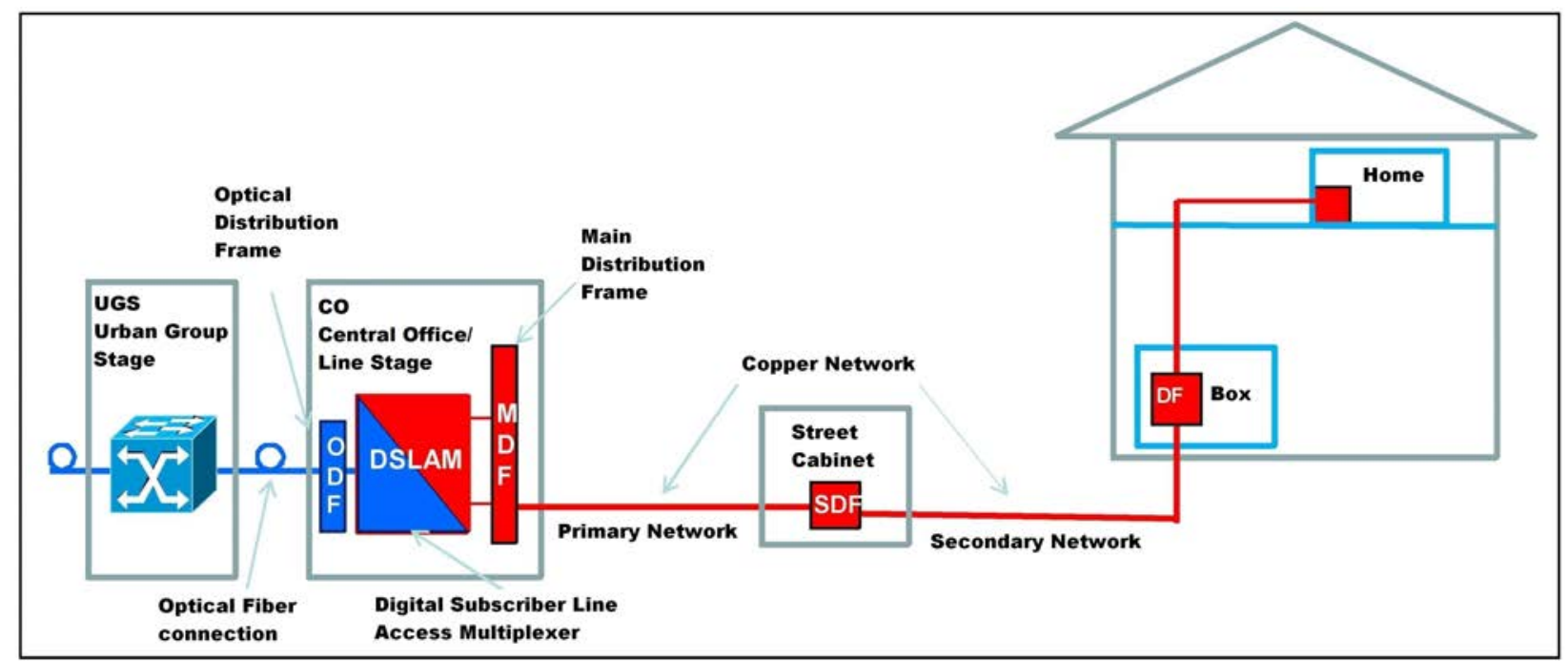

The figure illustrates the main elements of the "Fiber To The Exchange"system characterizing the Italian ADSL infrastructure. The system involves a copper-wire connection between the end user premises and the closest Central Office, and a fiber optic connection between the Central Office and the closest Urban Group Stage. Source: (AGCOM, 2011). 
Figure B.3: Distribution of ADSL Coverage and Location of UGS in Tuscany

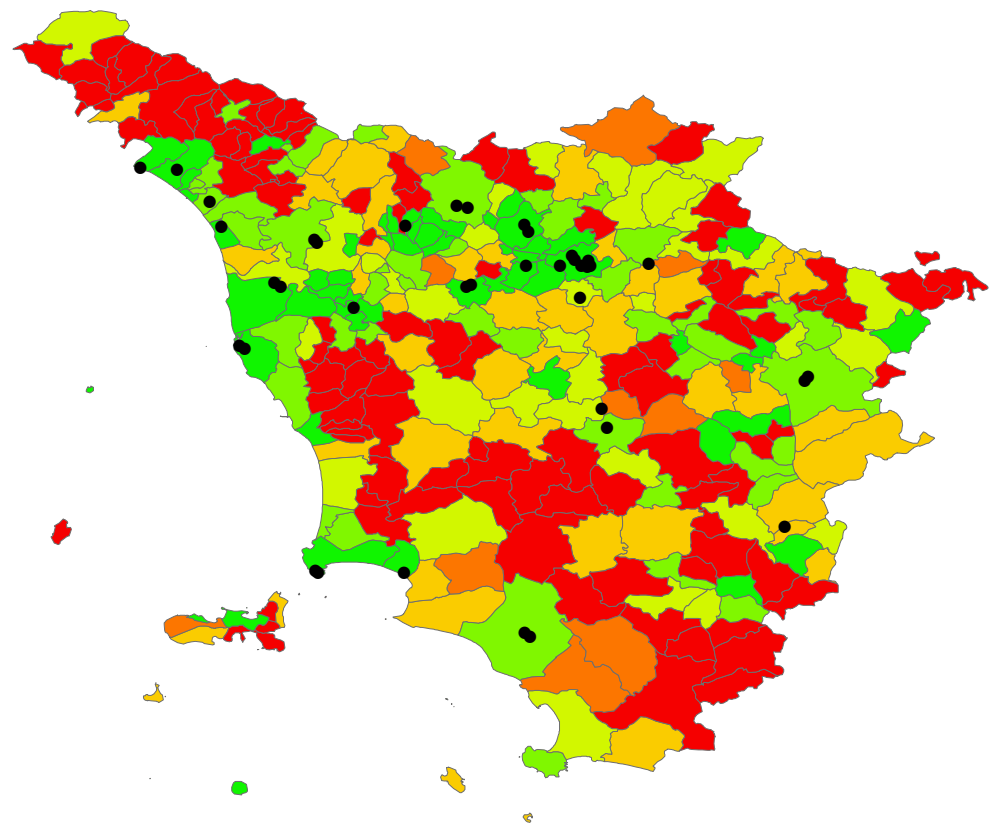

The figure reports the distribution of access to ADSL Internet services across municipalities as of 2005 and the location of UGSs for the region of Tuscany, with ADSL access increasing from darker (limited access) to lighter colors (full access).

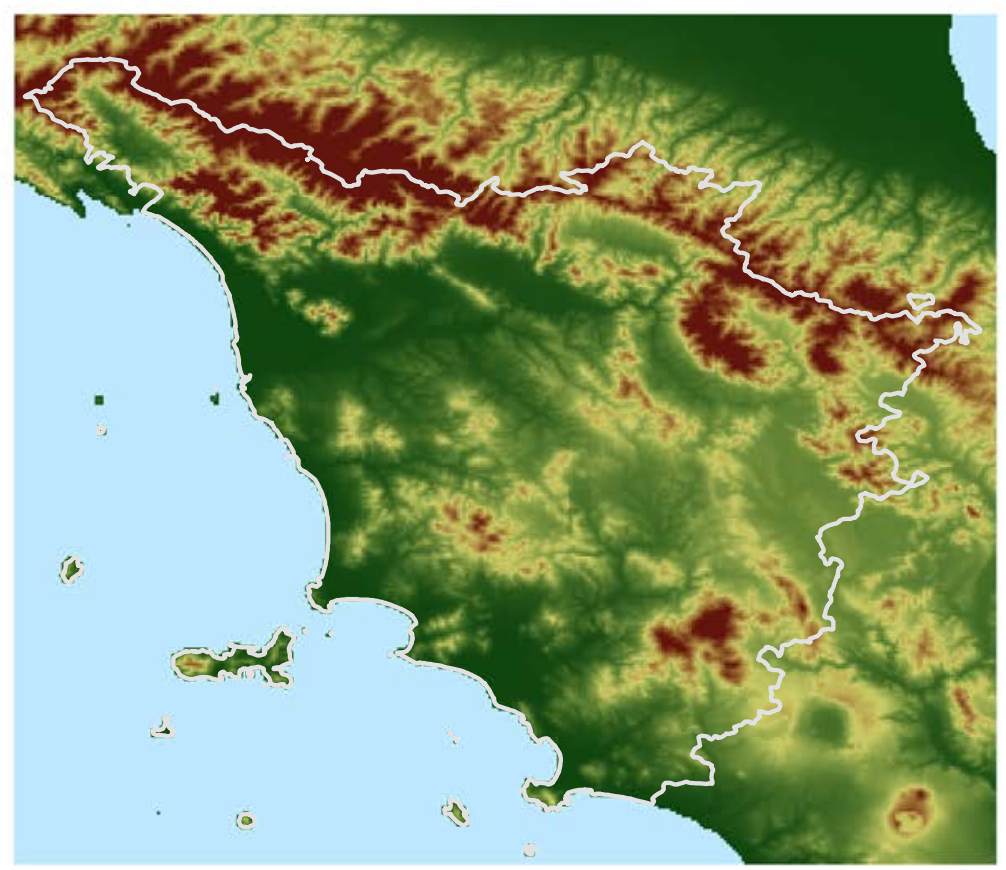

The figure reports the topographic map of Tuscany. The comparison between this map and the one reported in figure B.3 illustrates the relationship between terrain characteristics and access to ADSL technology. 
Figure B.5: Evolution of ADSL Coverage (2005-2010)

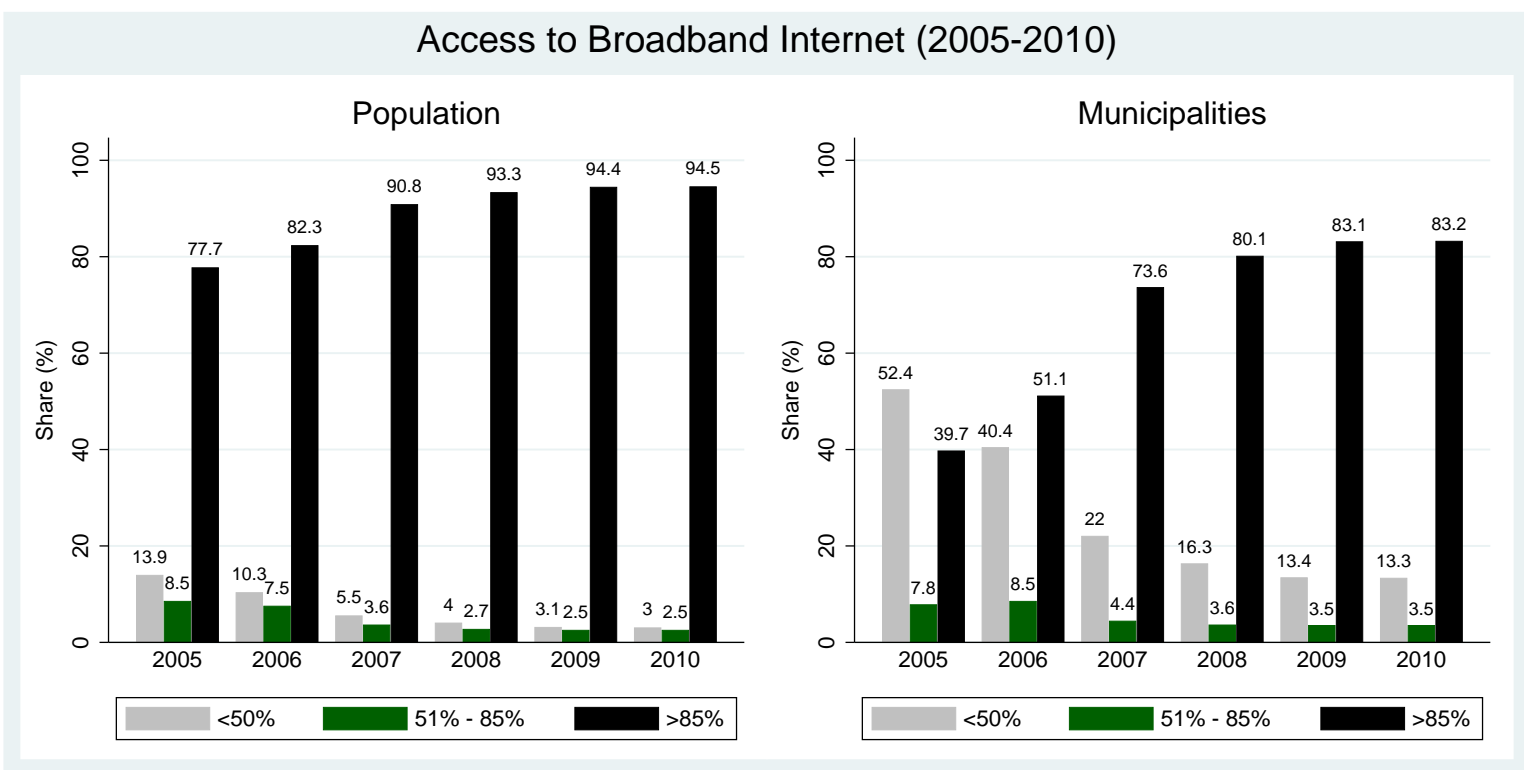

The figure reports the distribution of ADSL coverage by year with the percentage of household with ADSL access increasing from grey (limited access) to black (full access). Source: Between.

Figure B.6: Broadband Penetration and Broadband Access, regional level (2006)

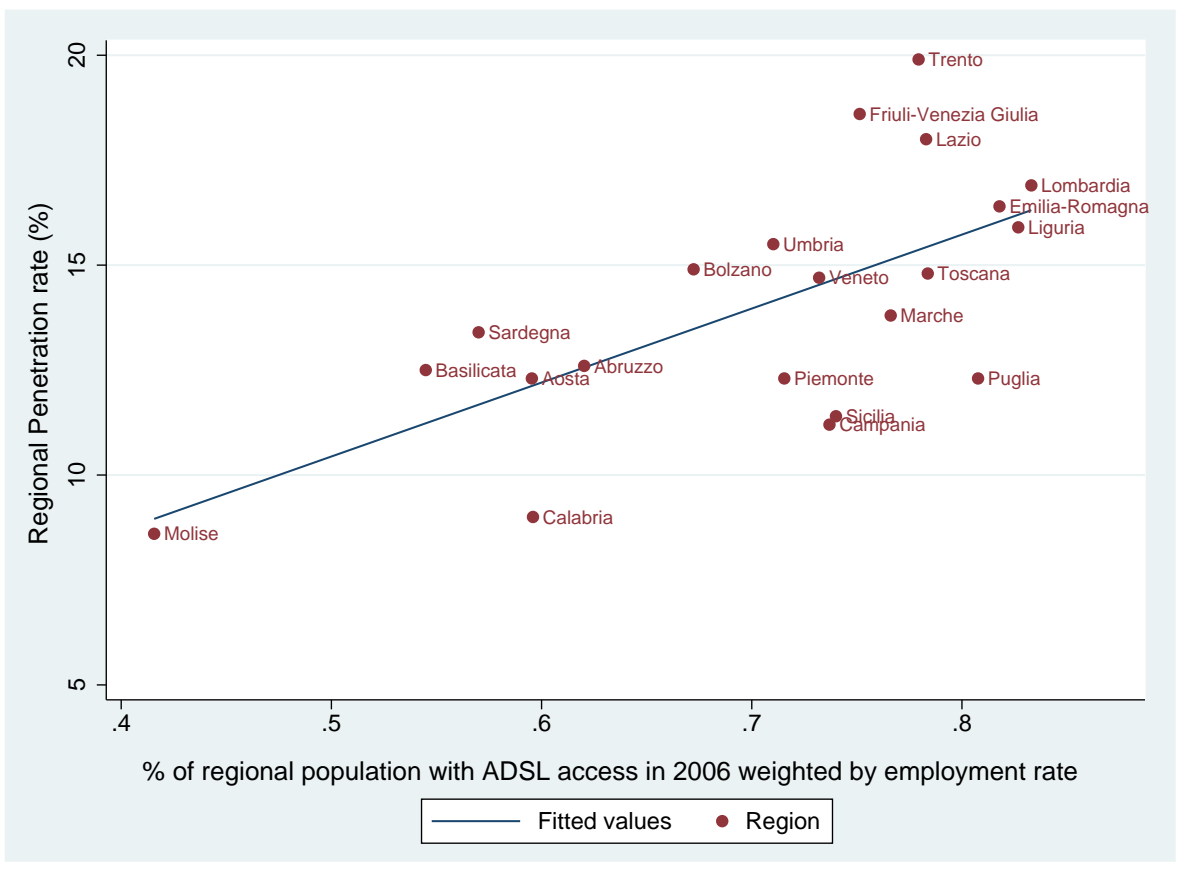

The figure reports the scatterplot of regional broadband penetration against our measure of broadband access for 2006. Source (ISTAT 2013; Between) 